\title{
Extracellular Calcium Controls the Expression of Two Different Forms of Ripple-Like Hippocampal Oscillations
}

\author{
Paloma Aivar, Manuel Valero, Elisa Bellistri, and Liset Menendez de la Prida \\ Instituto Cajal, Consejo Superior de Investigaciones Científicas (CSIC), Madrid E-28002, Spain
}

\begin{abstract}
Hippocampal high-frequency oscillations (HFOs) are prominent in physiological and pathological conditions. During physiological ripples $(100-200 \mathrm{~Hz})$, few pyramidal cells fire together coordinated by rhythmic inhibitory potentials. In the epileptic hippocampus, fast ripples $(>200 \mathrm{~Hz}$ ) reflect population spikes (PSs) from clusters of bursting cells, but HFOs in the ripple and the fast ripple range are vastly intermixed. What is the meaning of this frequency range? What determines the expression of different HFOs? Here, we used different concentrations of $\mathrm{Ca}^{2+}$ in a physiological range (1-3 mM) to record local field potentials and single cells in hippocampal slices from normal rats. Surprisingly, we found that this sole manipulation results in the emergence of two forms of HFOs reminiscent of ripples and fast ripples recorded in vivo from normal and epileptic rats, respectively. We scrutinized the cellular correlates and mechanisms underlying the emergence of these two forms of HFOs by combining multisite, single-cell and paired-cell recordings in slices prepared from a rat reporter line that facilitates identification of GABAergic cells. We found a major effect of extracellular $\mathrm{Ca}^{2+}$ in modulating intrinsic excitability and disynaptic inhibition, two critical factors shaping network dynamics. Moreover, locally modulating the extracellular $\mathrm{Ca}^{2+}$ concentration in an in vivo environment had a similar effect on disynaptic inhibition, pyramidal cell excitability, and ripple dynamics. Therefore, the HFO frequency band reflects a range of firing dynamics of hippocampal networks.
\end{abstract}

Key words: drug delivery; fast ripples; high-frequency oscillations

\section{Introduction}

Sharp waves (SPWs) are local field potentials (LFPs) recorded in the hippocampus of primates and rodents during immobility and slow-wave sleep (Buzsáki et al., 1983; Skaggs et al., 2007). Accompanying SPWs are high-frequency oscillations (HFOs) termed ripples (100-200 Hz) occurring at the pyramidal cell layer (Suzuki and Smith, 1988; Buzsáki et al., 1992; Skaggs et al., 2007). SPW ripples are proposed to play mnemonic roles by acting to replay neuronal traces (Skaggs and McNaughton 1996; Lee and Wilson, 2002; Dupret et al., 2010). In the epileptic hippocampus, different HFOs known as fast ripples $(>200 \mathrm{~Hz})$ have been described (Bragin et al., 1999; Jefferys et al., 2012). They have been related with epileptogenesis and are considered clinical biomarkers (Zijlmans et al., 2012).

Despite the role of normal and pathological HFOs, there is still poor understanding on their mechanisms. Physiological ripples

Received July 3, 2013; revised Jan. 8, 2014; accepted Jan. 10, 2014.

Author contributions: P.A. and L.M.d.I.P. designed research; P.A., M.V., E.B., and L.M.d.I.P. performed research; P.A. and L.M.d.I.P. analyzed data; L.M.d.I.P. wrote the paper.

This work was supported by Spanish Ministry of Science and Innovation Grant BFU2009-07989 and ERANETNeuron Project EPINET Grant EUI2009-04093. We thank Ivan Cohen for sharing his interface chamber design with us, Richard Miles for his generous support, comments, and discussion, and François Laurent for the MATLAB routine for the Hotelling's $t$ test. VGAT-Venus transgenic rats were generated by Drs. Y. Yanagawa, M. Hirabayashi, and Y. Kawaguchi at the National Institute for Physiological Sciences (Okazaki, Japan) using pCS2-Venus provided by Dr. A. Miyawaki. VGAT line progenitors were provided by the National Bioresource Project Rat (Kyoto, Japan). We thank Ane Altuna, Javier Berganzo, Luis J. Fernandez, Rosa Villa, and other colleagues from IKERLAN and National Center of Microelectronics-Spanish National Research Council for contributing to develop integrated fluidic probes. We also thank Elena Cid for helping with histological localization.

Correspondence should be addressed to Liset Menendez de la Prida, Cajal Institute, Spanish National Research Council, Avenida Doctor Arce, 37, Madrid E-28012, Spain. E-mail: Imprida@cajal.csic.es.

DOI:10.1523/JNEUROSCI.2826-13.2014

Copyright $\odot 2014$ the authors $\quad 0270-6474 / 14 / 342989-16 \$ 15.00 / 0$ are thought to mostly represent inhibitory potentials elicited from perisomatic innervating interneurons onto pyramidal cells (Ylinen et al., 1995; Csicsvari et al., 1999). In contrast, pathological fast ripples reflect PSs from clusters of glutamatergic neurons (Ibarz et al., 2010; Bragin et al., 2011). Data suggest that firing synchronization fundamentally differs between normal and pathological HFOs, with $\sim 10 \%$ pyramidal cells firing sparsely during ripples (Csicsvari et al., 2000) and larger pool of neurons tightly contributing to fast ripples (Ibarz et al., 2010).

HFOs are typically studied in slices. Given their low activity level, substances are added to enhance slice excitability (Gibson and McIlwain, 1965). Typically, $\mathrm{GABA}_{\mathrm{A}}$ receptor blockers, such as picrotoxin, are used to induce population bursts (Schwartzkroin and Prince, 1978; Schneiderman, 1986; Miles and Wong, 1987). Here, a pharmacologically induced disinhibitory state is associated with the emergence of paroxysmal HFOs similar to those recorded from epileptic foci (Ayala et al., 1973). In trying to deal with more physiological approaches, models were introduced by slightly changing cationic concentration (Draguhn et al., 1998; Ellender et al., 2010), using different cutting angles (Kubota et al., 2003; Wu et al., 2005) and slice thickness (Wu et al., 2005), priming activity by synaptic potentiation (Papatheodoropoulos and Kostopoulos, 2002; Behrens et al., 2005), and taking advantage of the highest connectivity of mouse slices (Maier et al., 2003; Hájos et al., 2013). Using these approaches, the cellular bases of HFOs have been examined, and theories are proposed on the complementary contribution of synaptic inhibition, excitation, ephaptic interactions, and gap junctions (Draguhn et al., 1998; Maier et al., 2003, 2011; Ellender et al., 2010). 
However, HFOs can be hardly classified as normal or pathological based only on their spectral features. What determines the expression of different HFOs? Here, we examine this issue by looking at the basic processes underlying HFOs in the normal hippocampus in vitro and in vivo. We found that, by slightly manipulating the physiological $\mathrm{Ca}^{2+}$ concentration, it resulted in the emergence of two forms of HFOs, similar to ripples and fast ripples. We demonstrate a major distinction of circuit dynamics underlying physiological and pathological HFOs and propose a role of disynaptic inhibition in controlling their expression.

\section{Materials and Methods}

Slice preparation and the adapted interface chamber. Juvenile male and female Wistar rats (17-22 d old) were used to prepare hippocampal slices. We also used a rat reporter line (VGAT-Venus A) in the Wistar background that expresses the yellow fluorescent protein (YFP) in almost the entire population of GABAergic cells (Uematsu et al., 2008). VGATVenus A progenitors were supplied by the National Bioresource Project Rat (Kyoto University, Kyoto, Japan). Horizontal slices $(400 \mu \mathrm{m})$ were prepared from the mid-septotemporal level of the hippocampus using a Leica vibratome (Leica VT1200S). Rats were anesthetized with ether and decapitated using procedures that met the European guidelines (86/609/ EEC). Extracellular solution (ACSF) contained the following (in $\mathrm{mm}$ ): $125 \mathrm{NaCl}, 4.25 \mathrm{KCl}, 1 \mathrm{MgCl}_{2}, 1.2 \mathrm{NaH}_{2} \mathrm{PO}_{4}, 22 \mathrm{NaHCO}_{3}$, and 10 glucose, pH 7.3 (when bubbled with $95 \% \mathrm{O}_{2}-5 \% \mathrm{CO}_{2}$ ). We used solutions with a range of concentrations of $\mathrm{CaCl}_{2}(1-3 \mathrm{~mm})$ to prepare and record hippocampal slices. The effect on chloride equilibrium was minimal with a theoretical reversal potential of approximately -72.3 and $-71.5 \mathrm{mV}$ for 3 and $1 \mathrm{mM} \mathrm{CaCl}_{2}$, respectively (see intracellular $\mathrm{Cl}^{-}$concentration in patch pipettes below). Slices were then storaged in an interface chamber with similar ACSF in which they recovered at room temperature for $1 \mathrm{~h}$ before temperature was set at $32^{\circ} \mathrm{C}$.

For recordings, we developed an interface chamber coupled to an upright microscope (BX51W; Olympus) to maintain slices in interface conditions while having access to visual patch. The chamber was fabricated in methacrylate (Lagoplast) by adapting a classical Haas-type design to fit into the available dimensions of the microscope. The chamber has a double-walled cylinder filled with a solution that is warmed and bubbled with $95 \%$ oxygen $-5 \%$ carbon dioxide gas. The recording solution enters the chamber via oxygen-impermeable Tygon tubes (R-3603, ref EW-06408-60; Cole-Parmer), which spiral in the heated solution before entering the upper part of the chamber in which the slice lies in a mesh. The top of the chamber is sealed with a removable cap, which creates a cavity for saturated and moistened gas mixture over the slice. Temperature is maintained to ensure that the recording chamber is at $32^{\circ} \mathrm{C}$. Specific details of the chamber can be found at our website technical blog (see Notes). Flow rate was set at $\sim 3 \mathrm{ml} / \mathrm{min}$. Neuron visualization was performed using a long working distance dry objective (LUC PlanFLN, $40 \times$; Olympus) that we warmed at $32^{\circ} \mathrm{C}$ to avoid vapor condensation. For recordings, one slice was transferred each time to the recording chamber.

In vitro electrophysiological recordings. In vitro extracellular field potentials, multiunit and single-unit activity, were recorded using either commercially available silicon-based tetrodes (A4x1-tet-3mm-150-312; Neuronexus) or 16-channel (16ch) linear arrays that we designed for in vitro applications (custom design: A16x1-2mm-100-413; Neuronexus). The linear array silicon probe (see Fig. $3 A$ ) was designed as a 16-tooth comb with one recording site per shank and $100 \mu \mathrm{m}$ shank-to-shank spacing to facilitate current-source density analysis in vitro. Impedance values were in the range of $0.7-1.4 \mathrm{M} \Omega$ for tetrodes and $0.9-1.3 \mathrm{M} \Omega$ for the $16 \mathrm{ch}$ comb. In some experiments aimed at recording extracellular field potential IPSPs, we used a patch-clamp pipette (borosilicate glass capillaries; outer diameter, $1.2 \mathrm{~mm}$; inner diameter, $0.69 \mathrm{~mm}$; Harvard Apparatus) filled with ACSF (tip resistance, $\sim 7 \mathrm{M} \Omega$ ) to facilitate repositioning while optimizing the extracellular signal with a single cell patched.

In vitro somatic patch-clamp recordings were made under visual control using an Axoclamp 2B amplifier (Molecular Devices). Patch re- cordings were performed using the whole-cell configuration in the current- and voltage-clamp modes. Patch pipettes were filled with intracellular solution containing the following: $113 \mathrm{~mm} \mathrm{~K}$-gluconate, $6 \mathrm{~mm}$ $\mathrm{KCl}, 1 \mathrm{~mm} \mathrm{MgCl}$, 1 mм NaCl, 1 mм EGTA, 5 mм HEPES, 2 mм K 2 ATP, $0.3 \mathrm{~mm}$ NaGTP, and $0.2 \mathrm{~mm}$ Alexa Fluor 568 and/or 0.5\% Neurobiotin (Vector Laboratories), pH 7.3 adjusted with $\mathrm{KOH}$ (osmolarity, 290-300 mOsm; impedance, 4-6 M $\Omega$ ). Capacitance compensation and bridge balance were performed over the recording session. Access resistance was determined from the cell response to subthreshold current pulses, compensated, and checked over the course of experiment. In voltage-clamp experiments, the membrane potential was held at several levels, typically from -85 to $-50 \mathrm{mV}$ to isolate spontaneous EPSCs and IPSCs and SPW-triggered currents. In a set of experiments, we included QX314chloride (5 mm; Alomone Labs) in the pipette to improve voltage-clamp conditions and to minimize voltage-dependent conductances at more depolarized holding potentials. The chloride equilibrium potential in this case was approximately $-60 \mathrm{mV}$. These experiments were performed under submerged conditions to avoid undesirable extracellular effect of QX314-chloride. The junction potential was not corrected. All recordings were simultaneously digitized (Digidata 1440A; Molecular Devices) and stored on disk at a sampling frequency $>10 \mathrm{kHz}$. For paired recordings of monosynaptic and disynaptic pairs, we also used slices of $250 \mu \mathrm{m}$ to facilitate visualizing deeper interneurons with preserved axonal terminals and to reduce intense background synaptic activity typically induced at $1 \mathrm{~mm} \mathrm{Ca}^{2+}$. In some experiments, we applied local extracellular stimulation with bipolar tungsten electrodes (square pulses of $0.1 \mathrm{~ms}$ duration and $0.5-1 \mathrm{~mA}$ amplitude).

Identification of neuronal types was achieved using morphological and electrophysiological criteria. Cells were initially classified as pyramidal cells or interneurons according to the following: (1) YFP fluorescence in the VGAT-Venus A reporter line; (2) firing response to depolarizing current pulses of $500 \mathrm{~ms}$ duration; and (3) specific features of their action potential waveforms. Interneurons were sampled from YFP-positive cells with somata at the stratum pyramidale to maximize recording from the population giving rise to perisomatic inhibition. This was further confirmed by the following: (1) extracellular recordings of IPSPs triggered by single action potentials of the recorded interneuron at monosynaptic latencies (0.4-0.8 ms; Glickfeld et al., 2009; Bazelot et al., 2010); (2) short half-width action potential duration $(0.2-0.8 \mathrm{~ms})$; (3) fast-spiking response; (4) large afterhyperpolarization (AHP) with duration at $25 \%$ in a range of 4.66-22.15 ms, consistent with parvalbumin-positive basket and axo-axonic cells (Papp et al., 2013); and (5) post hoc morphological reconstruction and colocalization with YFP. For anatomical identification, slices containing dye-loaded cells (Alexa Fluor 568 or Neurobiotin) were fixed during $30 \mathrm{~min}$ in $4 \%$ paraformaldehyde/0.1 M PBS, pH 7.4, after each experiment. Neurobiotin-loaded neurons were initially revealed with Alexa Fluor 568-conjugated streptavidin. Samples were mounted with homemade mowiol/propyl gallate $(50 \mathrm{mg} / \mathrm{ml})$ in $0.1 \mathrm{M}$ PBS. Stained cells were visualized with confocal microscope (TCS-SP5; Leica), using $z$-stack reconstructions at $2 \mu \mathrm{m}$ step size, and their GABAergic identity was further determined by fluorescence colocalization techniques for the green (enhanced YFP) and red (Alexa Fluor 568 or streptavidin) channel. In a number of experiments, cells loaded with Neurobiotin were subsequently visualized using avidin-biotinylated horseradish peroxidase complex reaction (Vector Laboratories).

In vivo recordings. In vivo recordings of ripples and fast ripples were obtained from normal $(n=3)$ and epileptic $(n=3)$ adult Wistar rats (250-400 g), respectively, using 16ch-silicon probes (linear arrays 100 $\mu \mathrm{m}$ spacing; Neuronexus) and the urethane (1.2 g/kg, i.p.) anesthetized preparation, as described previously (Ibarz et al., 2010). Epileptic rats were obtained using several low doses of systemic kainate injections as published previously (Suárez et al., 2011) and recorded 8 weeks after injection, when they already exhibited spontaneous seizures. Simultaneous $\mathrm{CA} 3$ and $\mathrm{CA} 1$ recordings were obtained by advancing the $16 \mathrm{ch}$ probe at $-3.0 \mathrm{~mm}$ posterior to bregma and $3.0 \mathrm{~mm}$ from the midline to target the pyramidal cell layer from both regions. A subcutaneous $\mathrm{Ag} / \mathrm{AgCl}$ wire was placed in the neck as a reference electrode. A concentric stimulating electrode at the contralateral CA3 region $(-1.2 \mathrm{~mm}$ from bregma, 2.9 $\mathrm{mm}$ from midline, $30^{\circ}$ in the sagittal plane) was used to characterize 
hippocampal responses. Stimulation consisted of biphasic square pulses of $0.2 \mathrm{~ms}$ duration and amplitudes of $0.1-0.6 \mathrm{~mA}$ every $5 \mathrm{~s}$. The input/ output response of CA1 region was evaluated with single-pulse stimulation of increasing intensity. We applied paired pulses at different intervals to evaluate paired-pulse inhibition (PPI; using intensities to evoke maximal PSs) and facilitation (PPF; using stimulation intensities aimed to generate EPSPs and intermediate PSs). The brain state was monitored with the $16 \mathrm{ch}$ silicon probe. In vivo data refer only to activities recorded during the large irregular state. Extracellular signals were preamplified $(4 \times$ gain) and recorded with a $16 \mathrm{ch}$ alternating current amplifier (model ME16-FAI- $\mu$ PA system; Multichannel Systems), further amplified by 100 , filtered by analog means at $1 \mathrm{~Hz}$ to $5 \mathrm{kHz}$, and sampled at $20 \mathrm{kHz} /$ channel with 12-bit precision.

Manipulation of $\mathrm{Ca}^{2+}$ concentration in vivo. We used an integrated tetrode-fluidic polymer probe (fprobe) fabricated in SU8 for simultaneous drug delivery and recordings in vivo (Microliquid; Altuna et al., 2013; see Fig. $8 A$ ). The fprobe was installed in a dedicated packaging to guarantee electrical and fluidic connections and advanced at coordinates to target the dorsal CA1 region at the stratus pyramidale $(-3.9 \mathrm{~mm}$ from bregma and $3.0 \mathrm{~mm}$ from midline). We avoid sampling large numbers of single-cell firing by gently repositioning the probe around the target area. For analysis, the channel with the poorest multiunit firing of the tetrode was chosen. Small volumes (typically $50 \mathrm{nl}$ ) of ACSF (in mm: $124 \mathrm{NaCl}, 5$ $\mathrm{KCl}, 1.5 \mathrm{MgSO}_{4}, 1.25 \mathrm{KH}_{2} \mathrm{PO}_{4}, 26 \mathrm{NaHCO}_{3}$, and 10 glucose, $\mathrm{pH} 7.3$ adjusted with $\mathrm{HCl}$ ) with different concentrations of $\mathrm{Ca}^{2+}$ and EGTA were gently delivered using a Hamilton syringe backfilled with oil and coupled to the fprobe. The concentration of $\mathrm{Ca}^{2+}$ and EGTA was estimated using the MaxChelator program (http://maxchelator.stanford. edu/) to locally reduce $\mathrm{Ca}^{2+}$ to 0 and $1 \mathrm{~mm}$. A soluble and fluorescent vital dextran, Texas Red $(0.25 \mathrm{mg} / \mathrm{ml}$; Invitrogen $)$ was added to the ACSF for subsequent histological localization. After completing the experiments, rats were perfused with $4 \%$ paraformaldehyde/0.1 м PBS. Hippocampal cells were stained blue using bisbenzimide.

Data analyses. Spectral analysis of LFP data was performed offline using routines written in MATLAB (MathWorks). Recordings were lowpass filtered at $100 \mathrm{~Hz}$ to study SPWs and bandpass filtered between 100 and $600 \mathrm{~Hz}$ to study HFOs, using forward-backward zero-phase finite impulse response (FIR) filters of order 512. For in vitro SPW-HFO events, the bandpass-filtered signal was subsequently smoothed using a Savitzky-Golay (polynomial) filter, and epochs of $\pm 200 \mathrm{~ms}$ were detected by thresholding ( $>2.5 \mathrm{SDs}$ ). For in vivo SPW-HFO events, we first detected sharp waves at the CA1 radiatum to trigger CA3 analysis, because CA3 SPW ripples in vivo are typically weaker than in CA1. CA3 ripples were then detected from these candidate events using similar criteria as for in vitro events $(>2.5$ SDs of the smoothed $100-600 \mathrm{~Hz}$ filtered trace). In the case of epileptic rats, we focused on large interictal events recorded in the CAl radiatum $(>1.5 \mathrm{mV})$ and proceeded similarly. All events were aligned by the peak of the accompanying individual SPW. Time-frequency representations were obtained by applying the multitaper spectral estimation in sliding windows with $97.7 \%$ overlap and a frequency resolution of $10 \mathrm{~Hz}$. To quantify the spectral organization, the spectrum was normalized by the power between 100 and 600 $\mathrm{Hz}$. The normalized power was treated as a statistical distribution, from which we extracted the mode, to estimate the peak frequency of field oscillations and the maxima power spectral value. HFO amplitude was evaluated from the $100-600 \mathrm{~Hz}$ filtered data. Data from several individual events from a given slice (in vitro) or animal (in vivo) were averaged to subsequently estimate a grand average for each condition ( 1 and $3 \mathrm{~mm}$ $\mathrm{Ca}^{2+}$ for in vitro data and normal and epileptic for in vivo data).

Current-source density (CSD) signals in vitro were calculated from the LFPs obtained using the $16 \mathrm{ch}$ comb. Data were represented as averages of 50-100 individual events. Offset differences were corrected before recordings started. Small impedance and offset differences between sites were responsible for the typical stripes detected in the background CSD. These small inhomogeneities were clearly separated from the relevant CSD response, which is associated with LFP events. Tissue conductivity was considered isotropic, and an arbitrary value of 1 was assigned to express CSD signals as millivolts per square millimeters.
Tetrode recordings were analyzed after high-pass filtering $(>360 \mathrm{~Hz})$ of LFPs using FIR-type digital filters and then exported to Offline Sorter (Plexon) for unit separation (thresholded at 4-5 SDs; $0.4 \mathrm{~ms}$ before threshold and $1 \mathrm{~ms}$ after threshold). We used sessions of $\sim 5 \mathrm{~min}$ with $>100$ SPW-HFO events. Units were sorted semiautomatically using different approaches, including principal components analysis of the spike amplitude and the slide amplitude. Abnormal waveforms were discarded. The firing autocorrelograms and cross-correlograms were inspected for contamination of the refractory period ( $2 \mathrm{~ms})$, central bins asymmetries, abnormal interactions, and other potential artifacts. Cells with low firing rate ( $<100$ spikes detected in the whole session) were not sorted. Cluster separation was evaluated with multivariate ANOVA. Units were classified as putative pyramidal cells or interneurons (Csicsvari et al., 1999) using information from the following: (1) the troughto-peak duration; (2) an asymmetry index (Bellistri et al., 2013); (3) the background firing rate histogram; and (4) the first moment of the autocorrelogram. CA3 pyramidal cells often fire bursts of two to five action potentials, yielding a characteristic autocorrelogram. We sorted a total of 56 units from $n=4$ slices from four rats, from which $66 \%$ (37 of 56) were classified as pyramidal cells and $27 \%$ (15 of 56) as interneurons. A number of sorted units ( 4 of 56) remained unclassified.

Perievent time histograms of sorted units were obtained by binning ( 2 $\mathrm{ms}$ ) single-unit data around the SPW peak. Single-cell responses (inhibitory, excitatory, and not modulated) were determined from the estimated $99 \%$ confidence interval.

Electrophysiological properties (input resistance and membrane time constant) of patch recorded neurons were measured using $500 \mathrm{~ms}$ subthreshold current steps in the whole-cell current-clamp mode. To determine action potential properties and the relationship between the firing frequency and the injected current ( $f / I$ curves), suprathreshold depolarizing pulses were used. Action potential threshold was defined at the inflection point of the voltage trace; action potential duration was defined at half-amplitude. In interneurons, AHP amplitude was calculated from the action potential threshold to the more negative peak of membrane potential after the spike. AHP duration at the $25 \%$ amplitude was estimated to check for electrophysiological criteria of parvalbuminpositive basket and axo-axonic cells (Papp et al., 2013). For estimation of the resting membrane potential, no holding current was applied. These properties were evaluated during the first $2-3 \mathrm{~min}$ after breaking the seal.

Spontaneous EPSCs and IPSCs were detected with the MiniAnalysis software (version 6.0.7; Synaptosoft). IPSCs $\left(\mathrm{GABA}_{\mathrm{A}}\right.$ mediated, $V_{\text {rev }}=$ $-65.8 \pm 1.5 \mathrm{mV}$ ) were detected as positive outward currents at membrane potentials between -50 and $-60 \mathrm{mV}$. EPSCs (glutamatergic, estimated $V_{\text {rev }}=10.1 \pm 6.1 \mathrm{mV}$ ) were detected as negative inward currents at holding membrane potentials approximately $-60 \mathrm{mV}$. In addition, we relied on opposite polarities for event detection. Synaptic event separation was refined by accounting for the rise time of individual synaptic currents, which are faster than their decay, to further optimize detection under condition of event overlapping. No differences were found in the frequency of EPSCs detected at -70 and $-60 \mathrm{mV}$ in pyramidal cells and interneurons at $1 \mathrm{~mm} \mathrm{Ca}^{2+}$ (see Notes), further validating the detection method. Moreover, we used QX314 in a set of experiments to examine IPSCs $\left(V_{\text {rev }}=-58.5 \pm 1.1 \mathrm{mV}\right)$ and EPSCs $\left(V_{\text {rev }}=-4.1 \pm\right.$ $1.8 \mathrm{mV}$ ) at more depolarized potentials. In all cases, we obtained group cumulative probabilities of the amplitude and frequency of the spontaneous synaptic events recorded during sessions of $1 \mathrm{~min}$ for different holding potentials. An excitatory-to-inhibitory index (E-I index) was defined as the ratio between the mean frequency (amplitude and charge) of spontaneous EPSCs and IPSCs per cell in each condition (1 or $3 \mathrm{~mm}$ $\left.\mathrm{Ca}^{2+}\right)$. An E-I index above 1 indicates a hyperexcitable state dominated by excitation, whereas an E-I index below 1 indicates a dominance of inhibition. Because of intense EPSP bombardment during transition from 3 or $1 \mathrm{mM} \mathrm{Ca}^{2+}$, individual IPSCs were not reliably detected.

Extracellular IPSPs (fIPSPs) were detected after triggering LFP recordings by the presynaptic action potentials. fIPSPs were all-or-none, and their amplitude, latency, and probability distribution were assessed using 50-100 spikes. Latency between the presynaptic spike and the fIPSP was calculated following Bazelot et al. (2010), from the peak of the intracellular spike to the onset of the extracellular event. We estimated the prob- 
ability of coincident spikes and fIPSPs using information from the distribution of the interspike and inter-fIPSP intervals for each experiment. This estimation provides a chance level probability $(0.16-0.26)$ for statistical comparisons.

Analysis of in vivo fluidic experiments was performed by a combination of methods. Spontaneous ripples were detected from the tetrode channel exhibiting the poorest multiunit contribution using similar criteria than for in vitro events. We also tested for changes of PPI, as a measure of disynaptic GABAergic transmission, by using two stimulation pulses ( 25 $\mathrm{ms}$ ), giving raise to the maximal PS, as adjusted in each case. A PPI ratio was calculated as the ratio between the second and the first PS. To evaluate changes of PPI ratios caused by lowering $\mathrm{Ca}^{2+}$ concentration, a PPI index was calculated from the PPI ratio after and before delivery. We also checked for PPF using two stimulation pulses (150 ms), giving raise to EPSPs or an intermediate PS. A PPF ratio and PPF index were estimated as explained previously for PPI. To evaluate changes in excitability of pyramidal cells after lowering $\mathrm{Ca}^{2+}$ concentration, we estimated an input/output curve and used intermediate PSs to compare data from different experiments.

Statistical analysis was performed using SPSS 18.0 for Windows and MATLAB. All results are given as means $\pm S D$, with the number of cells (or slices) indicated in every case. Comparison of HFO spectral features was performed with two-tailed unpaired Student's $t$ tests. For cumulative distribution of EPSCs and IPSCs, significant differences were checked with the Kolmogorov-Smirnov test. Mean frequency and amplitude data, as well as the E-I index, independently obtained in 1 and $3 \mathrm{~mm}$ $\mathrm{Ca}^{2+}$ were further assessed by unpaired Student's $t$ tests. Data from transition experiments (same slice and cell in 3 and $1 \mathrm{mM} \mathrm{Ca}^{2+}$ ) were compared using paired Student's $t$ tests. Differences of the E-I index was tested against 1 using a one-sample $t$ test. The default significance level was at $p=0.05$, unless otherwise specified. Separation of probability data in the 3 versus $1 \mathrm{~mm}$ plot (see Fig. $7 H$ ) was tested using the Hotelling's $t$ test on the Mahalanobis distance. In vivo data before and after delivery was analyzed using paired Student's $t$ tests for each experiment.

\section{Results}

\section{Physiological- and pathological-like HFOs in vitro and} in vivo

Horizontal slices were prepared from the mid-septotemporal level of the rat hippocampus and recorded in a modified interface chamber coupled to an upright microscope (see Materials and Methods). Using a combination of multisite and patch-clamp recordings in current-clamp mode (Fig. 1C), we found major differences in the cellular dynamics of spontaneous SPW-HFO events recorded with two different $\mathrm{Ca}^{2+}$ concentrations. More than $60 \%$ of slices prepared and recovered in $3 \mathrm{mM} \mathrm{Ca}^{2+}$ generated spontaneous SPWs and associated HFO activity that originated in CA3 with amplitudes of a few hundred microvolts (Fig. $1 A 1)$ and frequencies in a range of $100-200 \mathrm{~Hz}$ (Fig. 1A2). The

\section{In vitro}
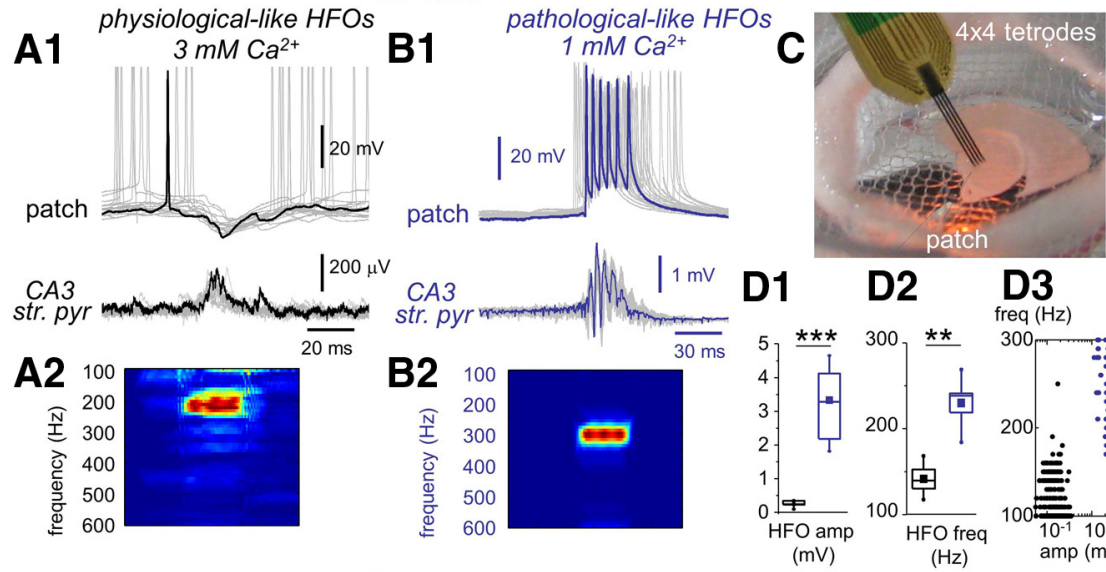

D3

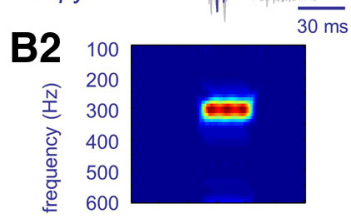

In vivo

A3 physiological ripples $\mathbf{B 3}$ interictal fast ripples
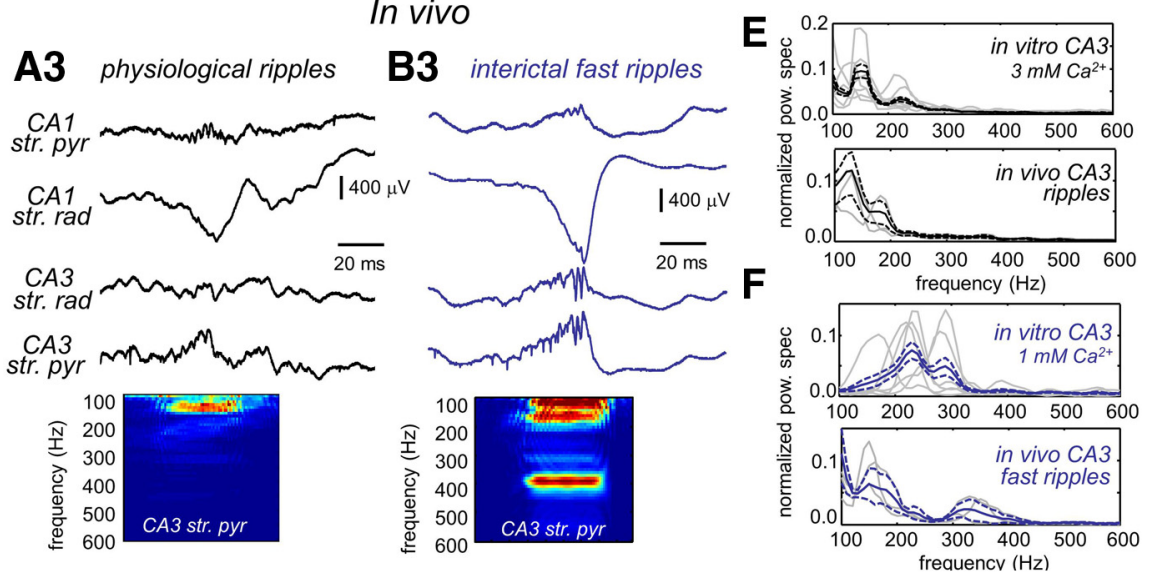

Figure 1. Physiological- and pathological-like HFOs. A1, Representative example of simultaneous extracellular and pyramidal cell patch recording during physiological-like HFO 0 in $3 \mathrm{~mm} \mathrm{Ca}^{2+}$.A2, Time-frequency spectrum of the LFP recorded at the stratum pyramidale in $\mathbf{A 1}$. A3, In vivo recording of physiological ripples using $16 \mathrm{ch}$ silicon probes. One representative example is shown. For sake, only data from relevant hippocampal strata at CA3 and CA1 are shown. str. pyr, Stratum pyramidale; str. rad, stratum - frequen spectrum of the LEP recorded at the CA3 stratum pyramidale is shown at the bottom B1, Example

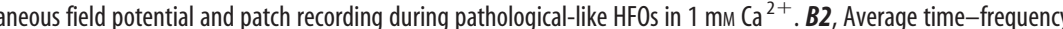

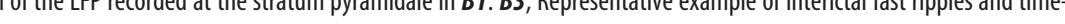
record slices in interface conditions especially suitable for releasing spontaneous SPW-HF0 events. A silicon-based tetrode $(4 X)$ HFO frequency (freq; D2) in $3 \mathrm{~mm}$ (black, $n=6$ slices) and $1 \mathrm{~mm}$ (blue, $n=6$ slices) $\mathrm{Ca}^{2+}$.D3, Group differences of HFO frequency amplitude of each individual event clearly show clustering of data from $3 \mathrm{~mm}$ (black) and $1 \mathrm{~mm}$ (blue) $\mathrm{Ca}^{2+}{ }^{2+} \boldsymbol{E}$, Top, Normalized 列 $3 \mathrm{~mm} \mathrm{Ca}^{2+}$ (data from 6 slices from 6 rats). Bottom, Same for CA3 SPW-HFO events recorded in vivo from normal rats ( ments and the grand average of SPW-HFO events recorded in vitro at $1 \mathrm{~mm} \mathrm{Ca}^{2+}$ ( 6 slices from 6 rats). Bottom, Same for CA3 SPW-HFO events recorded in vivo from epileptic rats $(n=3) .{ }^{* *} p<0.01 ;{ }^{* * *} p<0.001$.

remaining $40 \%$ of slices (data not shown) exhibited brief field events consistent with isolated extracellular inhibitory potentials (fIPSPs) and multiunit activity, as described previously (Bazelot et al., 2010). As already reported (Kubota et al., 2003; Ellender et al., 2010), simultaneous patch-clamp recordings from neighboring CA3 pyramidal cells confirmed that, during SPWs, many neurons were hyperpolarized by rhythmic barrages of IPSPs ( $V_{\text {rev }}=-68.2 \pm 6.5 \mathrm{mV}, n=4$ cells) at approximately similar frequencies (Fig. 1A1; Maier et al., 2011). These in vitro HFOs mimic SPW ripples recorded in vivo at the CA3 stratum pyramidale (Fig. 1A3), in terms of both their irregular amplitude and the associated single-cell dynamics as reported previously (Ylinen et al., 1995; Wittner et al., 2007). We directly compared the properties of CA3 ripples recorded in vivo and in vitro and found that 


\section{A}
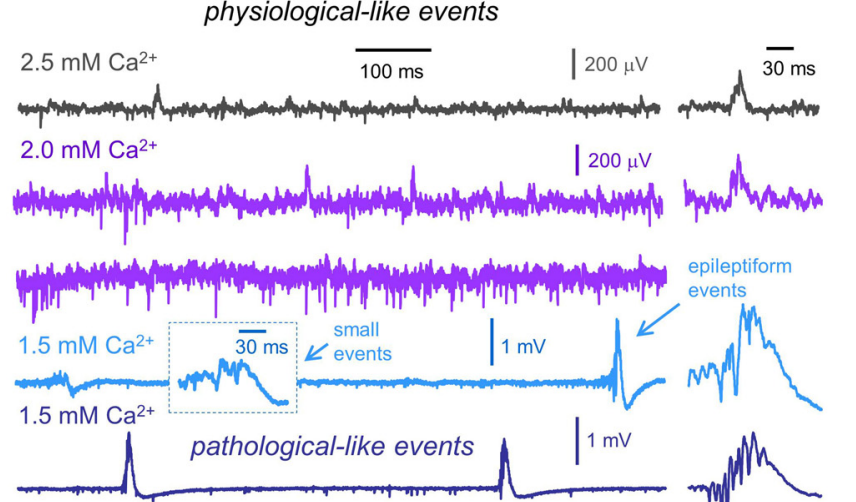

C

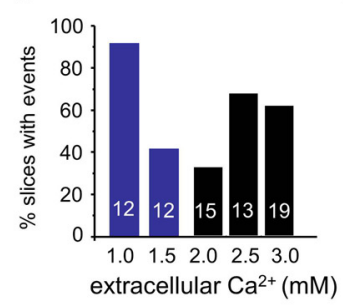

D

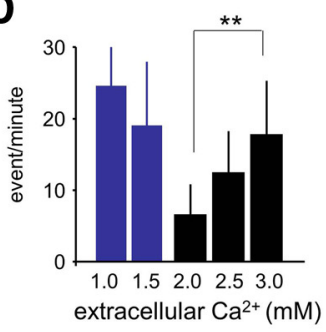

B

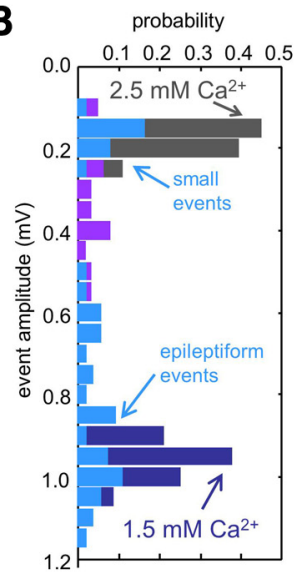

E

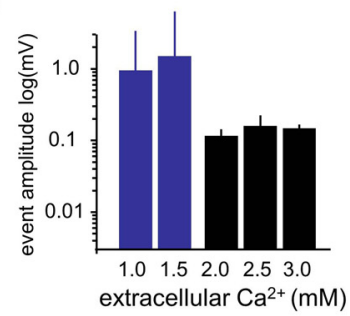

Figure 2. Effect of extracellular $\mathrm{Ca}^{2+}$ on the features of spontaneous SPW-HFO events. $\boldsymbol{A}$, Representative examples of the types of SWP-HFO events typically recorded in a range of extracellular $\mathrm{Ca}^{2+}$ concentration. Note the large multiunit activity recorded at $2 \mathrm{~mm} \mathrm{Ca}^{2+}$ (purple) in slices not exhibiting spontaneous SPW-HFO events. Using $1.5 \mathrm{~mm} \mathrm{Ca}{ }^{2+}$ resulted in some slices exhibiting spontaneous SPW-HFO events of different amplitudes that were difficult to classify (light blue), whereas clear pathological SPW-HFO events were seen in others (dark blue). $\boldsymbol{B}$, Amplitude histograms of all events detected in the representative slices shown in $\boldsymbol{A}$. Note two clear peaks for small and large events detected in the slice at $1.5 \mathrm{~mm} \mathrm{Ca}^{2+}$ (light blue, bottom trace). $\boldsymbol{C}$, Dependence of the percentage of slices exhibiting spontaneous events on different extracellular $\mathrm{Ca}^{2+}$ concentration. Numbers indicate the total number of slices tested. $\boldsymbol{D}$, Dependence of the rate of spontaneous SPW-HFO events on different extracellular $\mathrm{Ca}^{2+}$ concentration. ${ }^{* *} p<0.0001$. E, Dependence of event amplitude on different extracellular $\mathrm{Ca}^{2+}$ concentrations.

they similarly exhibited spectral peaks within the $100-200 \mathrm{~Hz}$ range (Fig. 1E). The mean ripple frequency in vivo $(117 \pm 12 \mathrm{~Hz}$; 88 events from 3 rats) was not different from the mean HFO frequency in vitro under $3 \mathrm{mM} \mathrm{Ca}^{2+}(126 \pm 13 \mathrm{~Hz}, 346$ events from 6 slices from 6 rats; $p=0.1183$ ). In vitro SPW ripple-like events were reversibly blocked by $10 \mu \mathrm{M}$ CNQX ( $n=4$ slices $)$ and low concentrations of gabazine $(0.2-1 \mu \mathrm{M} ; n=4$ slices $)$, suggesting both glutamatergic and fast GABAergic underlying signaling. Neither $100 \mu \mathrm{M}$ APV ( $n=3$ slices) nor $5 \mu \mathrm{M}$ CGP52432 (3-[[(3,4-dichlorophenyl)-methyl] amino]propyl] (diethoxymethyl)phosphinic acid; $n=6$ ) blocked them (see Notes).

In contrast, $>90 \%$ slices bathed in $1 \mathrm{mM} \mathrm{Ca}^{2+}$ exhibited highamplitude spontaneous HFOs (Fig. 1B1), with frequencies in the $150-300 \mathrm{~Hz}$ range (Fig. 1B2). Simultaneous extracellular and patch-clamp recordings showed that most CA3 pyramidal cells discharge at similar frequencies (Fig. 1B1), as reported previously (Foffani et al., 2007). Contrary to SPW-HFO events recorded in $3 \mathrm{mM} \mathrm{Ca}^{2+}$, their amplitude was one order of magnitude larger (Fig. 1D1), suggesting that much more neurons were contributing to generate these large LFPs. The frequency of SPW-HFOs recorded in $1 \mathrm{mM} \mathrm{Ca}^{2+}$ typically invaded the lower fast ripple band (200-300 Hz; Fig. 1D2), which rarely occurs for events recorded at $3 \mathrm{mM} \mathrm{Ca}^{2+}$ in vitro (Fig. 1D3) and in normal rats in vivo (Fig. $1 E$ ). Instead, they somehow resemble fast ripples recorded in epileptic animals (Fig. 1B3,F). Interictal CA3 fast ripples in vivo had a mean frequency of $196 \pm 77 \mathrm{~Hz}$ (42 events from 3 rats), not different from the frequency of SPW-HFOs events recorded in vitro under $1 \mathrm{mM} \mathrm{Ca}^{2+}(230 \pm 32 \mathrm{~Hz}, 142$ events from 6 slices from 6 rats; $p=0.3369$ ) but significantly higher than the mean $\mathrm{HFO}$ frequency of events under $3 \mathrm{~mm} \mathrm{Ca}{ }^{2+}$ $(p=0.0123)$. Although the spectrum of fast ripples in vivo is typically characterized by large spectral disorganization (Ibarz et al., 2010) that is better captured in vitro when slices are prepared from epileptic rats (Foffani et al., 2007), the dynamical features of SPW-HFOs obtained in slices from normal rats using $1 \mathrm{~mm}$ $\mathrm{Ca}^{2+}$ appeared reminiscent of abnormal neuronal dynamics. Thus, single-cell bursting behavior recorded at $1 \mathrm{mM} \mathrm{Ca}^{2+}$ in vitro suggests that these ripples better reflect PSs, in contrast to a major IPSP contribution under $3 \mathrm{~mm} \mathrm{Ca}^{2+}$ (Fig. $1 B 1$ vs A1). Blocking fast GABAergic inhibition with $0.2-1 \mu \mathrm{M}$ gabazine did not eliminate these events ( $n=4$ slices), but they were affected by blocking glutamatergic transmission with $10 \mu \mathrm{M}$ CNQX $(n=4$ slices). Neither $100 \mu \mathrm{M}$ APV ( $n=3$ slices) nor $5 \mu \mathrm{M}$ CGP52432 $(n=3)$ blocked spontaneous SPW-HFO events under 1 $\mathrm{mM} \mathrm{Ca}^{2+}$ (see Notes). Therefore, these data advocate claiming SPW-HFOs recorded at $3 \mathrm{~mm} \mathrm{Ca}^{2+}$ as physiological-like events, whereas SPW-HFOs recorded at 1 $\mathrm{mM} \mathrm{Ca}{ }^{2+}$ are more likely to reflect some degree of pathological-like dynamics.

\section{Different forms of SPW-HFOs in vitro depend on the extracellular $\mathrm{Ca}^{2+}$ concentration}

These data suggest that using two different $\mathrm{Ca}^{2+}$ concentrations has a major effect in the collective organization of single-cell firing during spontaneous SPW events recorded in vitro. Therefore, we tested different levels of extracellular $\mathrm{Ca}^{2+}$ in a physiological range from 3 to $1 \mathrm{~mm}$. For these experiments, we examined all the slices prepared from the equivalent midseptotemporal level from each given animal (three to seven animals per $\mathrm{Ca}^{2+}$ concentration). Spontaneous SPW-HFO events were detected using a common thresholding procedure in all slices, and amplitude distribution was then examined to look for different-sized events.

As in $3 \mathrm{mM} \mathrm{Ca}^{2+},>60 \%$ of slices prepared and recovered in $2.5 \mathrm{~mm} \mathrm{Ca}^{2+}$ (13 slices/4 rats) exhibited spontaneous SPW-HFO events of small amplitude (Fig. 2A, dark gray). Event detection showed single peaked histograms at a few hundred microvolts (Fig. 2B, dark gray). Using $2 \mathrm{~mm} \mathrm{Ca}{ }^{2+}$ resulted in a significant reduction of the proportion of slices exhibiting spontaneous SPW-HFO events ( 30\%, 15 slices/7 rats; Fig. $2 C)$. The remaining $70 \%$ of slices typically showed multiunit activity and some isolated fIPSPs (Fig. $2 B$, purple). The rate of these spontaneous SPW-HFO events dropped significantly in $2 \mathrm{mM} \mathrm{Ca}^{2+}$ compared with events detected in $3 \mathrm{mM} \mathrm{Ca}^{2+}$ (Fig. $2 D ; p<0.0001$ ), but the amplitude was similar (Fig. 2E). When $1.5 \mathrm{mM} \mathrm{Ca}^{2+}$ was used (12 slices/ 3 rats), we observed large SPW-HFO events in $\sim 40 \%$ slices (Fig. $2 A$, dark blue bottom trace). In these cases, event detection showed single peaked histograms with amplitudes in the millivolt range (Fig. $2 B$, dark blue), similar to pathological-like events recorded in $1 \mathrm{mM} \mathrm{Ca}^{2+}$ (Fig. $\left.1 D, E\right)$. In some slices prepared and 
recorded at $1.5 \mathrm{mM} \mathrm{Ca}^{2+}$, event detection exhibited two peaks at the histogram corresponding to the previously described small and large epileptiform events (Fig. $2 A, B$, light blue). These events were not classified. Slices not exhibiting large SPW-HFO events at $1.5 \mathrm{~mm} \mathrm{Ca}^{2+}$ were typically dominated by large multiunit activity.

Hence, our data suggest that using two extreme levels of $\mathrm{Ca}^{2+}$ concentration in a physiological range (1-3 mM) reveals the spontaneous emergence of two forms of HFOs in hippocampal slices. Therefore, we chose to look at the mechanisms underlying the collective emergence of these two HFO patterns.

\section{Profiles of sinks and sources of physiological- and pathological-like SPW events}

We used linear array silicon probes designed for in vitro applications (Fig. $3 A$ ) to look at the spatial organization of synaptic sinks and sources underlying the two types of spontaneous SPW-HFO events. Given the event-toevent variability of HFO timing, we chose to look at the underlying SPW activity because it reflects the major synaptic drive giving rise to population events. SPWs underlying HFO events recorded in $3 \mathrm{mM} \mathrm{Ca}^{2+}$ were characterized by a sharp negativity of the LFP in the apical dendritic layers in association with positive deflection at the cell body layer (Fig. 3B). CSD analysis confirmed the presence of a dendritic sink at the stratum radiatum and a synaptic source at the stratum pyramidale (Fig. 3B). Given the inhibitory nature of the SPW-associated potentials recorded intracellularly (Fig. 1A1), these somatic positive deflections likely reflect active synaptic sources caused by inward chloride currents. Pharmacological experiments suggest that recurrent glutamatergic connections are critical for SPW-HFO emergence, and therefore the dendritic sink would probably reflect an active synaptic component as well (Ellender et al., 2010; Sullivan et al., 2011).

Examination of the SPW spatial profiles recorded at $1 \mathrm{~mm}$ $\mathrm{Ca}^{2+}$ suggests similar pattern of sinks (dendritic) and sources (somatic; Fig. 3C), despite their larger amplitude compared with physiological-like events recorded at $3 \mathrm{mM} \mathrm{Ca}^{2+}$. However, the predominance of suprathreshold depolarizing responses in intracellular recordings (Fig. 1B1) and pharmacological experiments suggests that the somatic positive deflections were more interpretable in this case as return current sources. Comparison of CSD profiles confirmed similar patterns for physiological- and pathological-like SPW-HFO events being difficult to discern on their active or passive character without intracellular information (Fig. 3D; $n=5$ slices each condition). Therefore, SPW CSD signals are ambiguously related with both physiological- and pathological-like associated HFOs

\section{Different neuronal dynamics during physiological and pathological HFOs}

We next looked at the organization of neuronal firing by extracting single-unit activity from tetrode recordings (Fig. 4A1). We used semiautomatic cluster analysis to sort units, which were then classified as putative interneurons or pyramidal cells de- pending on their trough-to-peak duration and a waveform asymmetry index (Bellistri et al., 2013), together with information about their firing pattern (see Materials and Methods).

Similar to in vivo SPW ripples (Csicsvari et al., 2000), sparse firing increases were observed to occur during physiological-like SPW events at $3 \mathrm{mM} \mathrm{Ca}^{2+}$ (Fig. 4A2). Nearly half of putative pyramidal neurons $(46 \%, 17$ of 37; Fig. 4A3) exhibited firing suppression, and $\sim 41 \%$ ( 15 of 37 ) were found to fire action potentials. The remaining $13 \%$ of pyramidal cells did not exhibit significant firing modulation (5 of 37 units; data not shown). Interestingly, some of the pyramidal cells that fired during physiological events exhibited rhythmic bursting slightly faster than LFP HFO (175 $\pm 21 \mathrm{~Hz}, n=5$ units; Fig. 4A3). In contrast to pyramidal cells, most putative interneurons fired during physiological HFOs (73\%, 11 of 15 ; Fig. 4A3), typically with single or at most double action potentials. Only one putative interneuron was found to be inhibited during the events, and close to $27 \%$ interneurons did not exhibit significant firing modulation (data not shown). Pathological-like HFO events recorded at $1 \mathrm{~mm}$ $\mathrm{Ca}^{2+}$ showed quite different firing dynamics, with unit sorting being virtually impossible because of strong firing overlap during HFOs (Fig. $4 B$ ).

\section{Intracellular correlates of physiological- and pathological-like HFOs}

We next obtained whole-cell recordings from both pyramidal cells and stratum pyramidale interneurons in the two different conditions using slices prepared from a rat reporter line (VGATVenus A) that expresses YFP in almost the entire population of GABAergic cells (Uematsu et al., 2008; Fig. 4C1,D1). We imposed strict morphological and electrophysiological criteria to maximize sampling from perisomatic innervating interneurons with somata at the stratum pyramidale (see Materials and Methods). As expected from the effect of different divalent cation concentration on neuronal excitability (Hille et al., 1975), neurons recorded under $3 \mathrm{~mm} \mathrm{Ca}^{2+}$ exhibited lower $f / I$ curves than those recorded under $1 \mathrm{mM} \mathrm{Ca}^{2+}$ for a similar concentration of $\mathrm{Mg}^{2+}$ (1 mM). This was the case for both pyramidal cells (Fig. 4C2,C3) and interneurons (Fig. 4D2,D3). Importantly, although the slope 


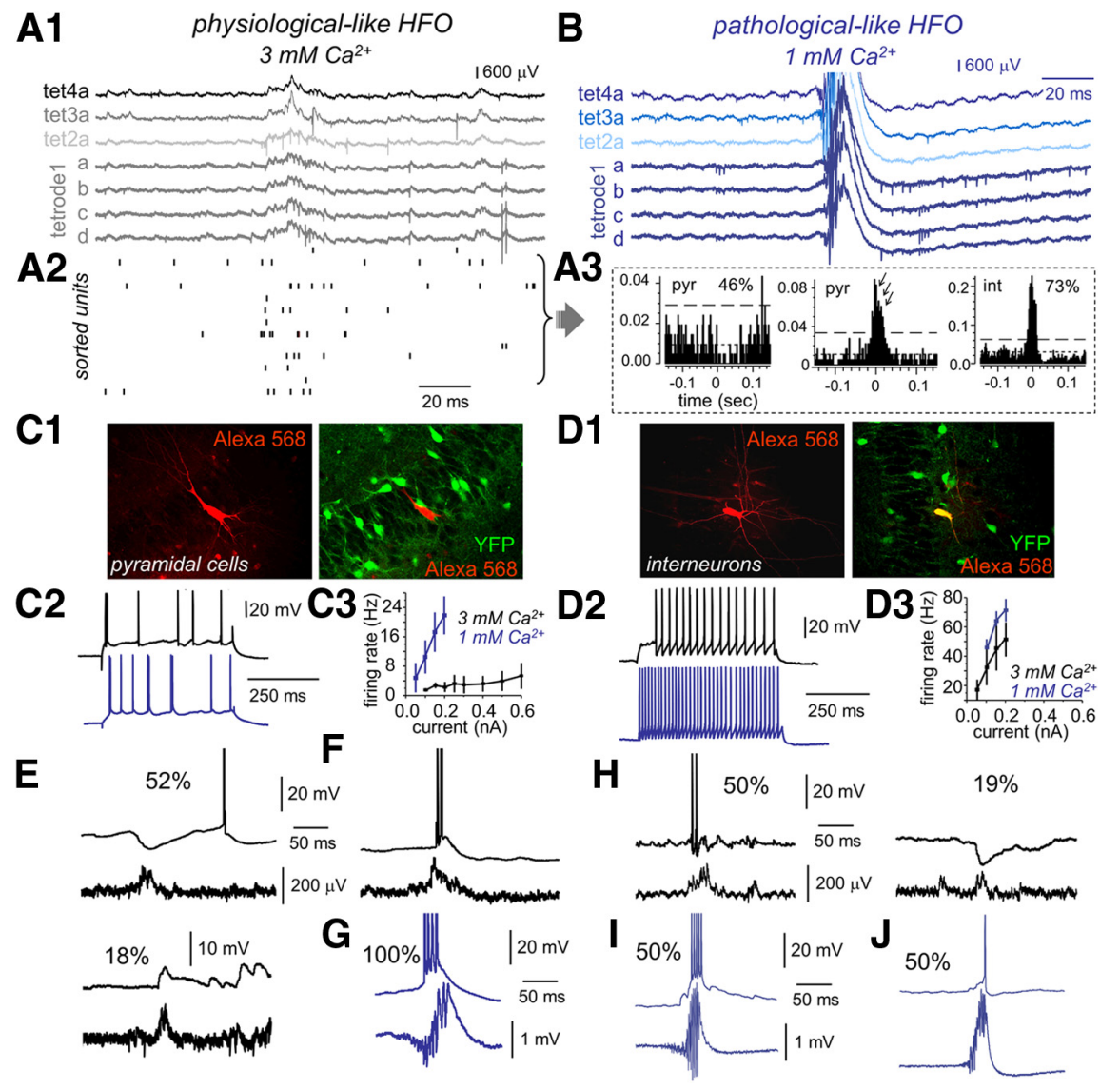

Figure 4. CA3 neuronal dynamics during physiological- and pathological-like HFOs. A1, Tetrode recordings were obtained to separate unit activity during physiological-like HFO in $3 \mathrm{~mm} \mathrm{Ca}^{2+}$. $\mathbf{A 2}$, Firing increases of sorted units were observed to occur during physiological-like events. Units from data shown in $\mathbf{A 1}$. A3, Representative single-cell data. Many putative pyramidal units (46\%) were inhibited during physiological-like HF0 events, whereas most interneurons (73\%) showed excitation. A minority of putative pyramidal cells fired burst during these events. $\boldsymbol{B}$, Representative tetrode recordings obtained during pathological-like HFOs in $1 \mathrm{~mm} \mathrm{Ca}{ }^{2+}$. C1, A rat reporter line (VGAT-Venus A) known to express YFP in most hippocampal interneurons was used to patch from different cell types. Patched pyramidal cells were stained with Alexa Fluor 568 for subsequent colocalization analysis. C2, Representative suprathreshold responses of two different pyramidal cells recorded in $3 \mathrm{~mm}$ (black) and $1 \mathrm{~mm}$ (blue) $\mathrm{Ca}^{2+} . \mathrm{C3}_{\text {, }}$ $\mathrm{f} / \mathrm{l}$ curves from pyramidal cells recorded in $3 \mathrm{~mm}$ (black, $n=23$ ) and $1 \mathrm{~mm}$ (blue, $n=9) \mathrm{Ca}^{2+}$. D1, Alexa Fluor 568 and YFP colocalization allowed identification of GABAergic interneuron. D2, Responses of two different representative interneurons recorded in $3 \mathrm{~mm}$ (black) and $1 \mathrm{~mm}$ (blue) $\mathrm{Ca}^{2+}$ for current pulses of $0.2 \mathrm{nA}$. D3, f/I curves from interneurons recorded in $3 \mathrm{~mm}$ (black, $n=21$ ) and $1 \mathrm{~mm}$ (blue, $n=11) \mathrm{Ca}^{2+}$. $\boldsymbol{E}$, Example traces of typical SPW-associated events recorded in pyramidal cells during physiological-like HFOs in $3 \mathrm{~mm} \mathrm{Ca}{ }^{2+}$. Many pyramidal cells exhibited clear SPW-associated inhibitory potentials (52\%), whereas some others received excitatory inputs (18\%). The remaining $17 \%$ cells did not show any SPW-associated response pattern. $\boldsymbol{F}, \mathrm{A}$ minority of cells had bursting activity. $G$, Representative example of a pyramidal cell recorded during pathological-like HF0 activity in $1 \mathrm{~mm} \mathrm{Ca}{ }^{2+}$. All recorded pyramidal cells were found to burst during HFO events. $\boldsymbol{H}$, Representative examples of the SPWassociated responses of interneurons during physiological-like HFO in $3 \mathrm{mM} \mathrm{Ca}^{2+}$. $I$, SPW-associated high-frequency burst was recorded in $50 \%$ interneurons in $1 \mathrm{~mm} \mathrm{Ca}^{2+}$. J, The remaining $50 \%$ of interneurons showed a variable participation typically contributing with single spikes in $1 \mathrm{~mm} \mathrm{Ca}^{2+}$

of the $f / I$ curve was significantly increased in pyramidal cells at $1 \mathrm{mM}$ $\mathrm{Ca}^{2+}(t=5.58, p=0.0051$; Fig. 4C3), no difference was found in interneurons $(t=2.15, p=0.0749)$, which only shifted the curve toward higher firing frequencies (Fig. 4D3). This suggests potential differences of extracellular $\mathrm{Ca}^{2+}$ in regulating intrinsic excitability of pyramidal cells and interneurons. Increased input resistance in interneurons but not in pyramidal cells at resting membrane potential could affect the $f / I$ curve slope and shift (Table 1). Actually, the Hille effect of the divalent fails to fully explain some of the effects of $\mathrm{Ca}^{2+}$ in these two cell types (e.g., time constant, action potential threshold), suggesting that extracellular $\mathrm{Ca}^{2+}$ is directly modulating voltage-dependent conductances.

We also took recourse of the reporter line to systematically evaluate intracellular responses of pyramidal cells and stratum pyrami- dale GABAergic interneurons during physiological- and pathological-like events. Consistent with tetrode data, pyramidal cells were typically inhibited during physiological HFO events (52\%, 28 of 54 cells), whereas some of them received excitatory inputs (18\%, 10 of 54; Fig. 4E). The remaining 30\% of pyramidal cells did not exhibit any clear SPW-associated synaptic event (data not shown). Among the cells that were depolarized during physiological-like events, a small percentage ( 5 of 54 cells) fired either single spikes or bursts of two to three action potentials similar to tetrode data (Fig. $4 F$ ). This scenario contrasted with the prominent bursting pattern found in all pyramidal cells during pathological-like HFOs events at $1 \mathrm{~mm}$ $\mathrm{Ca}^{2+}$ (12 of 12; Fig. 4G). Similar bursting activity of single pyramidal cells was confirmed previously with juxtacellular recordings (Foffani et al., 2007).

Interneurons from the stratum pyramidale typically fired during physiologicallike HFOs $(50 \%, 13$ of 26$)$, and some were inhibited (19\%, 5 of 26; Fig. $4 H$ ), in agreement with tetrode data. The remaining $31 \%$ of interneurons did not show any SPW-associated response pattern. As reported in others epileptic models of HFOs (Spampanato and Mody, 2007; Marchionni and Maccaferri, 2009), two major firing behaviors were seen in interneurons during pathological-like HFOs recorded in $1 \mathrm{~mm} \mathrm{Ca}{ }^{2+}$. Some GABAergic cells fired at high frequency during pathological events $(50 \%, 8$ of 16; Fig. 4I), whereas others exhibited a variable participation typically contributing with single spikes $(50 \%, 8$ of 16 ; Fig. $4 J)$.

Overall, these data support the idea that there are fundamental differences of network dynamics during physiologicaland pathological-like HFOs induced in vitro with different $\mathrm{Ca}^{2+}$ concentrations. Inhibitory responses dominate pyramidal cell firing during physiological-like events at $3 \mathrm{mM} \mathrm{Ca}^{2+}$, constraining in vitro activity to $\sim 30-40 \%$ of the population. Here, HFOs appear to partially reflect rhythmic IPSPs quite similar to in vivo ripples. In contrast, massive pyramidal cell bursting occurs during pathological-like events in vitro at $1 \mathrm{mM} \mathrm{Ca}^{2+}$. LFP HFOs now better reflect PSs generated by synchronous bursting, similar to fast ripples. Therefore, the same circuit can produce two forms of HFOs when extracellular $\mathrm{Ca}^{2+}$ is lowered in a physiological range. What are the mechanisms underlying such different network dynamics?

\section{Spontaneous EPSP and IPSP dynamics depend on extracellular $\mathrm{Ca}^{2+}$}

Because of the stronger firing observed during pathological HFOs, we hypothesized that superfusion with $1 \mathrm{mM} \mathrm{Ca}^{2+}$ should 
Table 1. Electrophysiological features of pyramidal cells and interneurons in 3 and $1 \mathrm{~mm}$ extracellular $\mathrm{Ca}^{2+}$ concentration

\begin{tabular}{|c|c|c|c|c|}
\hline & Pyramidal cells & & Interneurons & \\
\hline & $3 \mathrm{mmCa}^{2+}$ & $1 \mathrm{mmCa}^{2+}$ & $3 \mathrm{mmCa}^{2+}$ & $1 \mathrm{mmCa}^{2+}$ \\
\hline $\mathrm{RMP}(\mathrm{mV})$ & $-54.31 \pm 3.32^{* *}$ & $-60.55 \pm 6.80$ & $-50.11 \pm 5.74^{\S \S \S}$ & $-49.09 \pm 4.83^{\S \S \S}$ \\
\hline Resistance (M $\Omega$ ) & $108.19 \pm 28.81$ & $103 \pm 22.82$ & $145.27 \pm 43.68^{* * \S \S \S}$ & $220.85 \pm 101.97^{\S \S \S}$ \\
\hline Time constant (ms) & $15.24 \pm 4.09^{* *}$ & $9.43 \pm 6.24$ & $5.39 \pm 1.72^{\S \S \S}$ & $5.93 \pm 1.43$ \\
\hline AP threshold (mV) & $-38.06 \pm 5.82^{* * *}$ & $-48.58 \pm 7.15$ & $-34.78 \pm 5.93^{* * \S}$ & $-39.45 \pm 3.29^{\S \S \S}$ \\
\hline AP duration (ms) & $0.79 \pm 0.16$ & $0.79 \pm 0.23$ & $0.58 \pm 0.16^{\S \S \S}$ & $0.58 \pm 0.12^{\S \S}$ \\
\hline$n$ & 23 & 9 & 19 & 11 \\
\hline
\end{tabular}

RMP, Resting membrane potential; AP, Action potential. Resistance and time constant are estimated in current clamp at resting membrane potential with current pulses of $\pm 0.1 \mathrm{nA}$. All measurements were performed at resting membrane potential to assess how changes of intrinsic properties affect the integration of synaptic activity. ${ }^{*}$ Statistical comparisons between similar neuronal types in different calcium concentrations. ${ }^{\S}$ Statistical comparisons between different neuronal types in similar calcium concentrations. ${ }^{*, \S} p<0.05 ;{ }^{* *, \$ \S} p<0.01 ;{ }^{* * *, \$ s \S} p<0.001$.

be altering the inhibitory-to-excitatory balance. To directly test this point, we obtained whole-cell recordings in voltageclamp mode from identified pyramidal cells and GABAergic interneurons to look at the dynamic of excitatory and inhibitory synaptic currents.

In pyramidal cells, we observed clear differences of spontaneous EPSCs recorded at $-60 \mathrm{mV}(\sim 10 \mathrm{mV}$ driving force for IPSCs) under $3 \mathrm{~mm}$ ( $n=6$ cells $)$ versus $1 \mathrm{mM} \mathrm{Ca}^{2+}(n=6$ cells; Fig. $5 A 1, B 1)$, in frequency (Fig. 5C1, left; $p=0.014$ ), amplitude (Fig. 5D1, left; $p=0.017$ ), and charge (Fig. $5 E 1$, left; $p=0.001$ ). Higher EPSC frequency in $1 \mathrm{mM} \mathrm{Ca}^{2+}$ contrasted with lower frequency of spontaneous IPSCs recorded at this $\mathrm{Ca}^{2+}$ concentration (Fig. 5A1-C1, right). This was not attributable to poor IPSP detection caused by large numbers of EPSCs under $1 \mathrm{~mm}$ $\mathrm{Ca}^{2+}$, because the interevent interval of EPSCs recorded at $1 \mathrm{mM} \mathrm{Ca}^{2+}$ was similar at -60 and $-70 \mathrm{mV}$ (see Notes) Interestingly, an E-I index, estimated as the ratio between the frequency of spontaneous EPSCs and IPSCs per cell in each condition, indicated dominance of inhibition in $3 \mathrm{mM} \mathrm{Ca}{ }^{2+}$ $(0.71 \pm 0.23$, statistically different from 1 , $p=0.005$, one-sample $t$ test). In contrast, a substantially higher E-I index recorded from pyramidal cells in $1 \mathrm{mM} \mathrm{Ca}{ }^{2+}$ (13.76 $\pm 10.53, p<0.0001)$ suggests that they were exposed to a predominant excitatory synaptic drive. Similar results were obtained for the E-I ratio as estimated from the amplitude and charge of postsynaptic currents (Table 2).

Spontaneous synaptic activity was also evaluated in identified interneurons of the stratum pyramidale (Fig. 5A2,B2). We found more intense bombardment of excitatory activity in these cells when compared with pyramidal neurons under $3 \mathrm{mM} \mathrm{Ca}^{2+}$ $(p=0.032)$ but not under $1 \mathrm{mM} \mathrm{Ca}^{2+}(p=0.093)$. Mean EPSC frequency recorded in interneurons in $3 \mathrm{mM} \mathrm{Ca}^{2+}(n=6$ cells) was not different from the EPSC frequency in those recorded in 1 $\mathrm{mM} \mathrm{Ca}^{2+}(n=4$ cells; Fig. $5 C 2$, left; $p=0.081)$. In contrast, the mean IPSC frequency from interneurons recorded in $1 \mathrm{mM} \mathrm{Ca}^{2+}$ was significantly lower than that obtained from cells recorded in $3 \mathrm{mM} \mathrm{Ca}^{2+}$ (Fig. 5B2,C2, right; $p=0.013$ ). Again, this effect was
A1 pyramidal cells
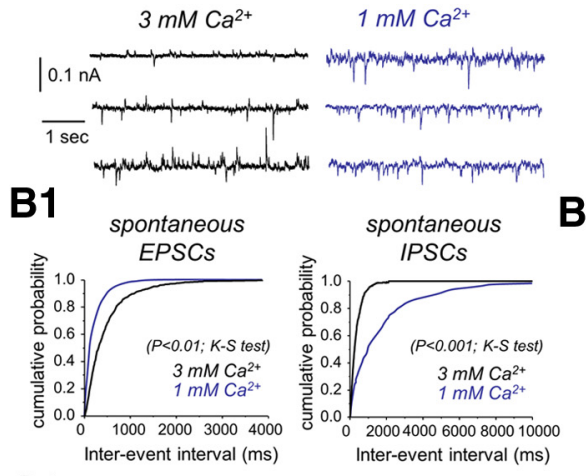

A2

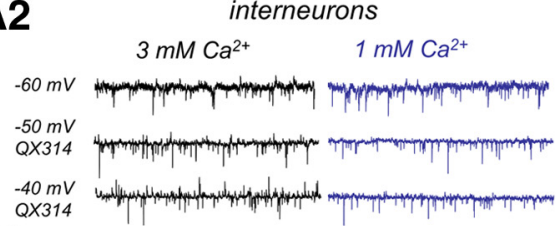

B2
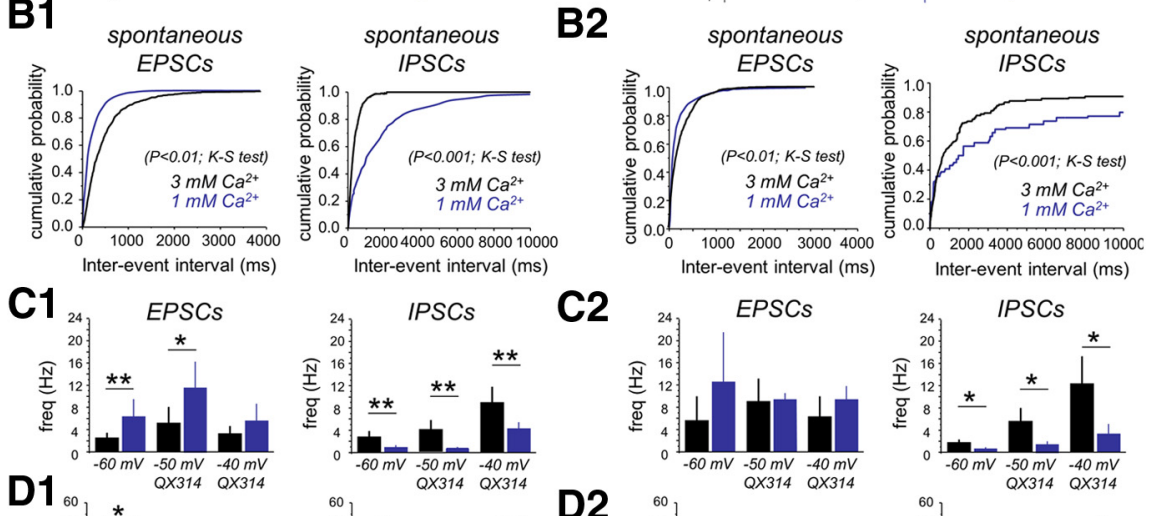

C2
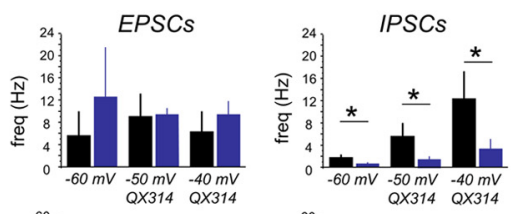

D2
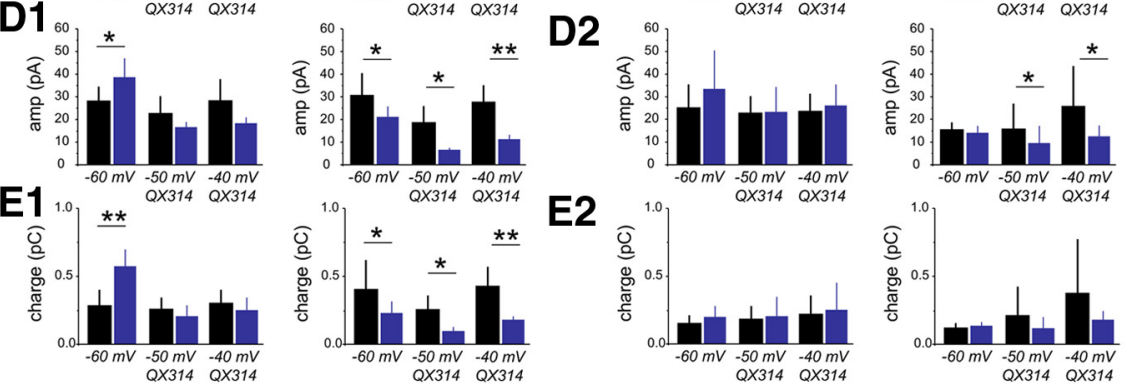

Figure 5. Spontaneous EPSC and IPSC dynamics in $3 \mathrm{~mm}$ and $1 \mathrm{~mm} \mathrm{Ca}{ }^{2+}$. A1, Spontaneous synaptic potentials were recorded from identified CA3 pyramidal cells at different membrane holding levels to detect excitatory (EPSCS) and inhibitory (IPSCS) components in $3 \mathrm{~mm}\left(n=6\right.$ cells) and $1 \mathrm{~mm}\left(n=6\right.$ cells) $\mathrm{Ca}^{2+}$. B1, Cumulative distribution of the interevent interval of spontaneous EPSCs (left) and spontaneous IPSCs (right) recorded at $-60 \mathrm{mV}$ in the two different $\mathrm{Ca}^{2+}$ concentrations. C1, Group data of mean frequency for spontaneous EPSCs (left) and IPSCs (right) as detected at $-60 \mathrm{mV}$ with standard pipette solutions (see Materials and Methods) and at different potentials with QX314. D1, Group data of mean amplitude for spontaneous EPSCs (left) and IPSCS (right). E1, Group data of total charge for spontaneous EPSCs (left) and IPSCS (right). A2, Spontaneous synaptic potentials recorded in identified interneurons in $3 \mathrm{~mm}(n=6)$ and $1 \mathrm{~mm}(n=4) \mathrm{Ca}^{2+} . B 2$, Cumulative distribution of the interevent interval of spontaneous EPSCS (left) and IPSCs (right) recorded from interneurons at the two different $\mathrm{Ca}^{2+}$ concentrations. C2, Group data of mean frequency for spontaneous EPSCs (left) and IPSCs (right). D2, Group data of mean amplitude for spontaneous EPSCs (left) and IPSCS (right). ${ }^{*} p<0.05$; ${ }^{* *} p<0.01$. E2, Group data of total charge for spontaneous EPSCS (left) and IPSCS (right).

not attributable to poor detection of IPSCs in interneurons at 1 $\mathrm{mM} \mathrm{Ca}^{2+}$ (see Notes). No difference was found in the amplitude (Fig. 5D2) or the charge (Fig. 5E2) of spontaneous EPSCs and IPSCs recorded at $-60 \mathrm{mV}$ in the two $\mathrm{Ca}^{2+}$ concentrations. Contrary to pyramidal cells, the E-I index calculated in interneurons was typically unbalanced toward excitation in both $3 \mathrm{mM} \mathrm{Ca}^{2+}$ $(5.64 \pm 4.07, n=6)$ and $1 \mathrm{mM} \mathrm{Ca}^{2+}(35.75 \pm 17.09, n=3$; or E-I ratios for the amplitude and charge; Table 2$)$. 


\begin{tabular}{|c|c|c|}
\hline & $3 \mathrm{mmCa}^{2+}$ & $1 \mathrm{mmCa}^{2+}$ \\
\hline \multicolumn{3}{|l|}{ Pyramidal cells } \\
\hline Frequency & $0.71 \pm 0.23$ & $13.76 \pm 10.53^{*}$ \\
\hline Amplitude & $0.91 \pm 0.21$ & $1.78 \pm 0.31^{*}$ \\
\hline Charge & $0.77 \pm 0.25$ & $2.48 \pm 0.66^{*}$ \\
\hline$n$ & 6 & 6 \\
\hline \multicolumn{3}{|l|}{ Interneurons } \\
\hline Frequency & $5.64 \pm 4.07$ & $35.75 \pm 17.09^{*}$ \\
\hline Amplitude & $1.79 \pm 0.59$ & $2.53 \pm 1.01$ \\
\hline Charge & $1.19 \pm 0.48$ & $1.71 \pm 1.19$ \\
\hline$n$ & 6 & 4 \\
\hline
\end{tabular}

Experiments were performed with standard pipette solution (see Materials and methods), and events were detected at $-60 \mathrm{mV} .{ }^{*} p<0.05$ for statistical comparisons between different calcium concentrations.

We performed an additional set of experiments using QX314 to improve voltage-clamp conditions and to examine postsynaptic currents at more depolarized holding potentials. Because detection was performed on inward and outward synaptic currents recorded simultaneously at a given potential, we looked for holding potentials giving comparable event amplitude and charge of opposite signs to minimize detection errors. In pilot experiments, we confirmed optimal detection of both EPSCs and IPSCs at -40 $\mathrm{mV}$, even under enhanced synaptic activity at $1 \mathrm{mM} \mathrm{Ca}^{2+}$. We also examined the dynamics of spontaneous synaptic events at $-50 \mathrm{mV}$ in these cells ( $\sim 10 \mathrm{mV}$ driving force for IPSCs) to compare with the previous dataset.

We confirmed the effect of extracellular $\mathrm{Ca}^{2+}$ on the EPSC and IPSC frequency for both pyramidal cells $(n=6)$ and interneurons ( $n=4$; Fig. $5 C 1, C 2)$ using QX314. Moreover, we confirmed increases of EPSC frequency at $1 \mathrm{mM}(7.07 \pm 2.35 \mathrm{~Hz})$ versus $3 \mathrm{mM} \mathrm{Ca}^{2+}(2.98 \pm 0.52 \mathrm{~Hz} ; p<0.0072)$ by holding pyramidal cells at the $V_{\text {rev }}$ of $\mathrm{GABA}_{\mathrm{A}}$ receptors. We could not proceed similarly with IPSCs at the reversal of glutamatergic currents because of strong contamination with voltage-dependent currents at holding potentials more depolarized than $-30 \mathrm{mV}$. The previously mentioned effect of extracellular $\mathrm{Ca}^{2+}$ on the amplitude (Fig. 5D1) and charge (Fig. 5E1) of EPSCs in pyramidal cells at $-60 \mathrm{mV}$ was probably attributable to poor voltage clamping and/or enhancement of EPSCs by voltage-dependent sodium conductances, because it was not reproduced at $-50 \mathrm{mV}$ with QX314 in the pipette. Altogether, these data confirm different E-I balance when hippocampal slices are prepared and recorded in two different concentrations of extracellular $\mathrm{Ca}^{2+}$. Accordingly, a slightly enhanced state of synaptic inhibition in 3 $\mathrm{mM} \mathrm{Ca}{ }^{2+}$ contrasted with a predominantly excitatory state when $1 \mathrm{mM} \mathrm{Ca}^{2+}$ is used.

\section{Transition from physiological- to pathological-like HFOs}

We next wondered whether a state transition from physiologicallike to pathological-like SPW-HFO events could be induced in slices by directly decreasing extracellular $\mathrm{Ca}^{2+}$ concentration. Simultaneous extracellular and patch recordings were used to monitor transition in single cells and LFPs when extracellular $\mathrm{Ca}^{2+}$ was decreased from 3 to $1 \mathrm{~mm}$ ( $n=17$ slices). Pyramidal cells recorded in $3 \mathrm{mM} \mathrm{Ca}^{2+}$ showed the typical inhibitory responses associated with field potential HFO in the ripple range (Fig. 6A, B1). Erratic unitary field IPSPs or fIPSPs were also detected in conjunction with intracellular IPSPs (Fig. 6B1, arrows), as described previously (Bazelot et al., 2010; Beyeler et al., 2013).

We found a consistent sequence of events when extracellular $\mathrm{Ca}^{2+}$ was decreased to $1 \mathrm{~mm}$. During the first $10 \mathrm{~min}$ after switch- ing to $1 \mathrm{~mm} \mathrm{Ca}^{2+}$, global firing increased in the form of multiunit activity recorded extracellularly (Fig. $6 A$; mean firing rate at $3 \mathrm{~mm}$ was $30.2 \pm 14.7 \mathrm{~Hz}$ vs $77.4 \pm 38.7 \mathrm{~Hz}$ at $1 \mathrm{~mm}, p=0.019 ; n=7$ slices). Part of this increase $(\sim 60 \%)$ can be explained by enhanced intrinsic excitability, as confirmed in slices recorded under a mixture of antagonist of synaptic transmission while decreasing $\mathrm{Ca}^{2+}$ to $1 \mathrm{~mm}$ ( $n=3$ slices; data not shown). Multiunit firing increase was typically associated with rises of spontaneous EPSP frequency in both pyramidal cells (Fig. $6 C-C 2 ; p=$ $0.0005 ; n=5$ cells) and interneurons (Fig. $6 D-D 2 ; p=0.0021$; $n=5$ cells). We also confirmed a significant increase of the mean firing rate in these two cellular populations (pyramidal cells, $p=$ 0.036, $n=6$, Fig. 6C3; interneurons, $p=0.019, n=5$, Fig. 6D3).

Within the first 10 min of transition, physiological-like HFO events were blocked, but a different type of population event then emerged associated with excitatory synaptic activity in the same cells that previously showed inhibition (Fig. $6 A, B 2$ vs $B 1$ ). These new events became of larger amplitude and progressively started recruiting pyramidal cell firing in the form of burst of action potentials (Fig. 6A). A closer examination revealed the presence of larger pathological-like field potential HFOs (Fig. 6B3). Full transition from spontaneous physiological- to pathological-like HFO activity occurred in $\sim 41 \%$ slices ( 17 of 41 ) and took between 7 and $15 \mathrm{~min}(8.2 \pm 2.9 \mathrm{~min})$. In slices in which spontaneous pathological-like events were not released, they could be elicited by extracellular stimulation (data not shown).

\section{Failure of GABAergic synaptic transmission under $1 \mathrm{mM} \mathrm{Ca}^{2+}$}

Altogether, these data support the idea that differences on neuronal excitability and E-I balance dictate the emergence of physiological or pathological forms of HFOs at different levels of $\mathrm{Ca}^{2+}$. Decreasing $\mathrm{Ca}^{2+}$ to $1 \mathrm{~mm}$ pushes the system toward a bursting excitable state. Thus, changes of excitatory and inhibitory forces underlie the transformation of physiological-like HFOs, typically associated with rhythmic IPSPs, in pathologicallike HFOs now better associated with pyramidal bursting. Strangely, interneurons also exhibited increases of EPSC frequency and firing rate, but this appeared to have contrasting effects on pyramidal cell activity, in which IPSP frequency decreased. What causes such disinhibitory effect of $1 \mathrm{mM} \mathrm{Ca}^{2+}$ ?

We reasoned that reducing extracellular $\mathrm{Ca}^{2+}$ to $1 \mathrm{~mm}$ could be differentially affecting GABAergic and glutamatergic transmission (Jones and Heinemann, 1987). To directly test this idea, we obtained paired recordings from monosynaptically connected cells to examine pyramidal-to-pyramidal (pyr-pyr) and pyramidal-to-interneuron (pyr-int) glutamatergic transmission, as well as interneuron-to-pyramidal (int-pyr) GABAergic transmission when extracellular $\mathrm{Ca}^{2+}$ is reduced. At $3 \mathrm{~mm}$ $\mathrm{Ca}^{2+}$, monosynaptic glutamatergic transmission was found to occur in 3 of 56 pyr-pyr pairs (Fig. $7 A$ ) and in 2 of 59 pyr-int pairs (Fig. $7 B$ ) at submillisecond latencies (pyr-pyr, $0.89 \pm 0.17 \mathrm{~ms}$; pyr-int, 0.56 and $0.68 \mathrm{~ms}, 0.62 \pm 0.08 \mathrm{~ms}$ ). Release probability was estimated at $0.97 \pm 0.05$ for pyr-pyr and $0.89 \pm 0.09$ for pyr-int (0.83 and 0.96). Monosynaptic GABAergic transmission was recorded in 2 of 59 pairs (Fig. 7C1) at latencies of $0.99 \pm 0.23$ $\mathrm{ms}$ ( 1.15 and $0.82 \mathrm{~ms}$ ) with high release probability of $0.95 \pm 0.08$ ( 1 and 0.89 ). We also tested for disynaptic GABAergic transmission (pyr-int-pyr) in pyramidal cell pairs (2 of 56) that were found to be connected via an intermediate interneuron (Fig. 7D1). Transmission delays in these pairs were consistent with disynaptic transmission $(1.91 \pm 0.03 \mathrm{~ms} ; 1.88$ and $1.92 \mathrm{~ms})$, and 
release probability was $0.83 \pm 0.06(0.87$ and 0.79 ), consistent with data from pyrint and int-pyr pairs.

We also took advantage of the extracellular visibility of IPSPs elicited by a single perisomatic interneuron (Glickfeld et al., 2009; Bazelot et al., 2010; Beyeler et al., 2013) to further test for monosynaptic (Fig. 7C2) and disynaptic (Fig. 7D2) GABAergic transmission. Similarly to monosynaptically connected pairs, 4 of 31 interneurons were found to generate an fIPSP at monosynaptic latency $(0.64 \pm$ $0.02 \mathrm{~ms})$ and high probability $(0.96 \pm$ $0.05)$ under $3 \mathrm{~mm} \mathrm{Ca}^{2+}$. Some pyramidal cells ( 7 of 66) were able to initiate disynaptic fIPSPs at latencies of $1.47 \pm 0.27$ and probability of $0.906 \pm 0.005$, consistent with our data from paired recordings.

We then tested directly for the effect of reducing extracellular $\mathrm{Ca}^{2+}$ on synaptic transmission. Although monosynaptic glutamatergic transmission was only moderately affected after $\mathrm{Ca}^{2+}$ lowering to $1 \mathrm{~mm}$ (pyr-pyr, $0.66 \pm 0.19, n=3$; pyr-int, $0.74 \pm 0.21, n=2,0.59$ and 0.88 ) being significantly higher than 0.5 probability (one-sample $t$ test, $p=0.0071$; Fig. $7 E$ ), monosynaptic GABAergic transmission was reduced below $0.5(0.37 \pm 0.07, n=2$, 0.32 and 0.42 ; Fig. $7 F$ ). Importantly, disynaptic inhibition was severely affected when dropping to $0.51 \pm 0.18(n=2,0.63$ and 0.38 ) in $1 \mathrm{~mm} \mathrm{Ca}^{2+}$ (Fig. $7 G$ ). Data from fIPSPs further confirmed these numbers. The probability of monosynaptic fIPSP dropped to $0.51 \pm 0.15$ at $1 \mathrm{~mm}$ $\mathrm{Ca}^{2+}\left(p=0.0042\right.$ vs $\left.3 \mathrm{mM} \mathrm{Ca}^{2+}\right)$. For disynaptic flPSPs, the probability dropped to $0.44 \pm 0.21\left(p=0.0041\right.$ vs $\left.3 \mathrm{mM} \mathrm{Ca}^{2+}\right)$. Similar effects of extracellular $\mathrm{Ca}^{2+}$ were detected in the efficacy (including failures) and the potency (excluding failures; Sasaki et al., 2012) of unitary synaptic transmission tested with paired recordings (Table 3).

Grouping together data from fIPSPs and paired recordings at 3 and $1 \mathrm{mM} \mathrm{Ca}^{2+}$ confirmed different effects of $\mathrm{Ca}^{2+}$ in glutamatergic and GABAergic transmission (Fig. $7 H$ ). Lowering $\mathrm{Ca}^{2+}$ to $1 \mathrm{~mm}$ had stronger effect on monosynaptic GABAergic (dots) than glutamatergic transmission (Fig. $7 H$, triangles; $t=9.754$, $p=0.0122 ;$ Hotteling's test on Mahalanobis distance). Similarly, disynaptic GABAergic transmission (squares) was more affected than monosynaptic glutamatergic transmission (Fig. $7 \mathrm{H}$, triangles; $t=5.77, p=0.05$; Hotteling's test). Monosynaptic and disynaptic GABAergic transmission were similarly affected. These data suggest that decreasing extracellular $\mathrm{Ca}^{2+}$ concentration has major effects on synaptic transmission in a circuit-specific manner, with monosynaptic glutamatergic and GABAergic transmission being differentially affected at $1 \mathrm{~mm} \mathrm{Ca}{ }^{2+}$. Importantly, the efficacy of disynaptic inhibition was strongly decreased at $1 \mathrm{mM} \mathrm{Ca}^{2+}$. Given the role of disynaptic inhibition in precisely controlling the timing of pyramidal cell firing, this suggests a major effect of lowering $\mathrm{Ca}^{2+}$ on the circuit ability to maintain an appropriate control of runaway excitation.

\section{Effect of manipulating $\mathrm{Ca}^{2+}$ concentration in vivo}

Finally, we chose to check whether locally manipulating the extracellular $\mathrm{Ca}^{2+}$ concentration in vivo has a similar effect on GABAergic transmission and SPW-HFO dynamics. To this purpose, we took advantage of an fprobe developed previously for simultaneous drug delivery and recording in vivo (Altuna et al., 2013). This consists of a tetrode-like probe of $90 \times 55 \mu \mathrm{m}$ dimensions with an integrated fluidic channel of $50 \times 20 \mu \mathrm{m}$ (Fig. $8 A$, front view and back view). A small volume is delivered through multiple outlet ports that give raise to an effective release area of $345 \mu \mathrm{m}^{2}$ (Fig. $8 A$ ). For these experiments, we targeted the $\mathrm{CA} 1$ region of the dorsal hippocampus while stimulating the contralateral CA3 region to check for PPI, as a measure of disynaptic GABAergic transmission and to monitor the PS response as a measure of pyramidal cell excitability (Fig. 8B). Spontaneous ripples were monitored at the CA1 


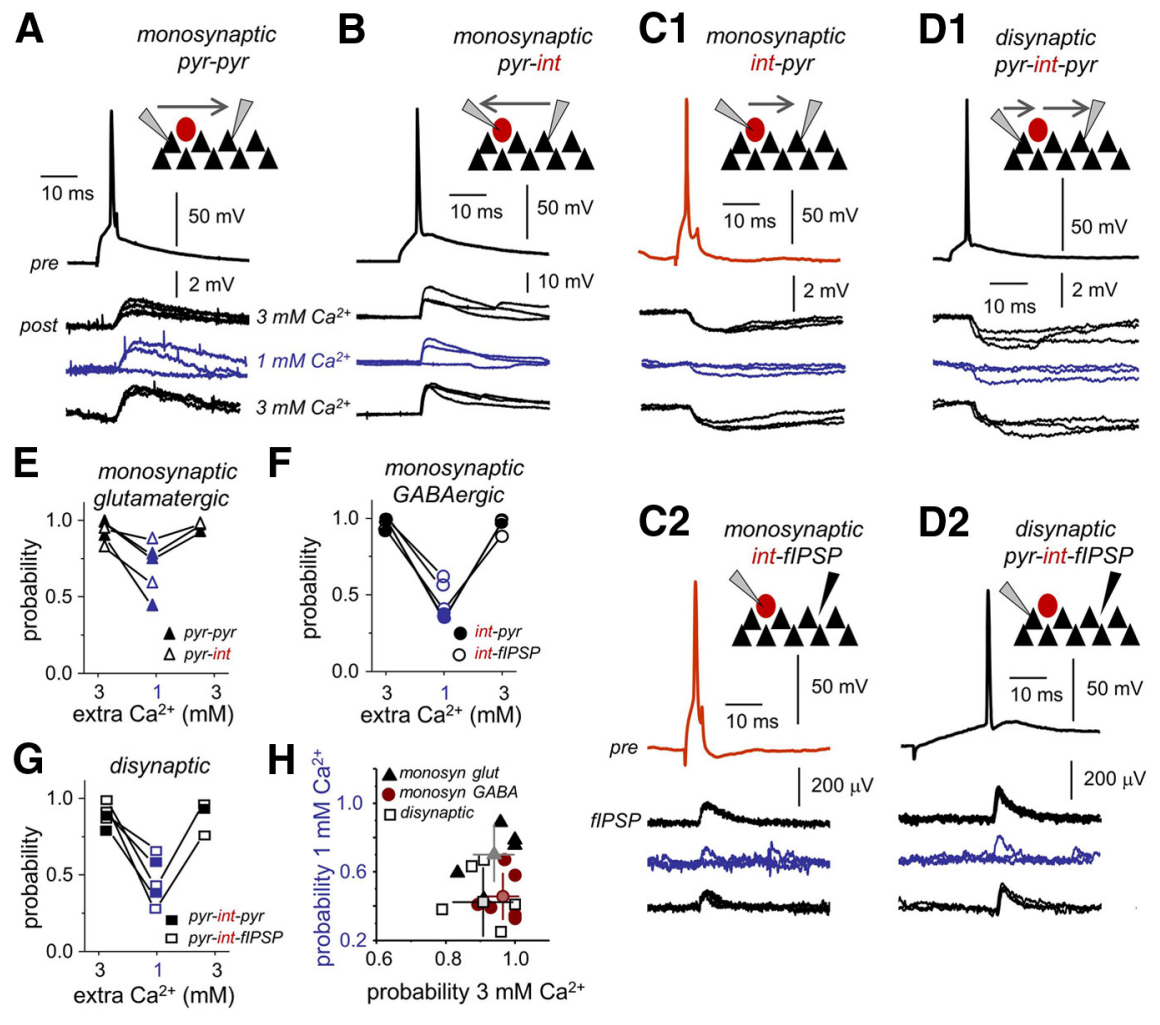

Figure 7. Effect of extracellular $\mathrm{Ca}^{2+}$ concentration on release probability. $\boldsymbol{A}$, Monosynaptic glutamatergic transmission was directly tested in paired recordings of CA3 pyramidal cells (pyr-pyr). Single action potentials in presynaptic CA3 pyramidal cell (pre) elicited EPSPs in the postsynaptic CA3 cell (post) as tested in 3 and $1 \mathrm{~mm} \mathrm{Ca}{ }^{2+}$. Current pulse duration was 5 ms. B, Monosynaptic glutamatergic transmission was also tested in pairs of CA3 pyramidal cells and interneurons (pyr-int). The reported VGAT-Venus A rat line was used to facilitate identification of pyramidal cells and interneurons. C1, Monosynaptic GABAergic transmission was evaluated with paired recordings of CA3 stratum pyramidale interneurons (presynaptic cell) and CA3 pyramidal cells (postsynaptic cell). C2, We also took advantage of the visibility of IPSPs at the LFP (fIPSP) to test for monosynaptic GABAergic transmission (int-fIPSP). Single action potentials in some interneurons were able to initiate an extracellular fIPSP at monosynaptic latencies. D1, Disynaptic inhibition was activated by some CA3 pyramidal cells at longer latencies compared with monosynaptic transmission, in postsynaptic pyramidal neurons recorded simultaneously (pyr-int-pyr). D2, Disynaptic inhibition was also confirmed in extracellular recordings of fIPSPs (pyr-int-fIPSP). In this example, current pulse duration was $350 \mathrm{~ms}$. $\boldsymbol{E}$, Release probability of monosynaptic glutamatergic transmission as tested in paired recordings of pyr-pyr (bold) and pyr-int (open). $\boldsymbol{F}$, Release probability of monosynaptic GABAergic transmission as tested in paired recordings of int-pyr (bold) and from the LFP int-fIPSP (open). G, Release probability of disynaptic GABAergic transmission as tested in paired recordings of pyr-int-pyr (bold) and from the LFP pyr-int-fIPSP (open). $\boldsymbol{H}$, Plot of the transmission probability in $3 \mathrm{~mm}$ versus $1 \mathrm{~mm} \mathrm{Ca}^{2+}$.

stratum pyramidale. Delivery was confirmed histologically by means of a soluble red dextran and typically affected a region of $\sim 50-70$ $\mu \mathrm{m}$ radius for $50 \mathrm{nl}$ (Fig. $8 C$ ).

To effectively manipulate $\mathrm{Ca}^{2+}$ concentration in vivo, we used the calcium chelator EGTA. Given the small volume to be affected and the difficulties to manipulate $\mathrm{Ca}^{2+}$ concentrations because of glial homeostasis (Zanotti and Charles, 1997), the concentration of EGTA and $\mathrm{Ca}^{2+}$ was selected to obtain free $\mathrm{Ca}^{2+}$ concentration of either nominally $0 \mathrm{~mm}$ (20 mM EGTA) or $1 \mathrm{~mm}\left(0.5 \mathrm{~mm}\right.$ EGTA and $1.5 \mathrm{~mm} \mathrm{Ca}^{2+}$; see Materials and Methods). We also checked for the effect to increase the extracellular $\mathrm{Ca}^{2+}$ concentration to $4 \mathrm{~mm}$.

Delivery of small volumes of 20 mM EGTA typically disorganized the spontaneous ripple events (Fig. 8D1, only one channel of the tetrode is shown). The characteristic ripple positivity transformed into a more spiky component that slightly accelerated, giving a complex power spectrum with multiple peaks that invaded the fast ripple band (Fig. $8 E 1, n=4$ rats) that are reminiscent of pathological-like SPW-HFO (Fig. 1B3; Foffani et al., 2007; Ibarz et al., 2010). Importantly, this change affected the shape of the LFP itself (Fig. 8D1, enlarged traces) and was not caused by increased multiunit firing. The mean spectral frequency increased from $185 \pm 15$ to $208 \pm 11 \mathrm{~Hz}$ after $20 \mathrm{mM}$ EGTA ( $p=0.043$; Fig. $8 E 1$, inset). Importantly, this effect ran in parallel with an impairment of PPI as tested with a maximal PS and $25 \mathrm{~ms}$ interval (Fig. $8 F 1, n=3$ rats tested), suggesting that disynaptic GABAergic transmission was affected. We also noted an increase of the intermediate PS (Fig. 8G1), suggesting that pyramidal cell excitability was increased similar to in vitro data (no change in PPF of intermediate spike). We observed mild effects of $0.5 \mathrm{~mm}$ EGTA (Fig. 8D2), with no clear changes in the dominant peak of the ripple spectrum but a minor disorganization of some events contributing to the fast ripple band (Fig. $8 E 2$, arrow, $n=2$ rats). There were minor effects on PPI (Fig. 8F2) and no clear effect on the amplitude of the intermediate PS (Fig. 8G2).

In contrast, locally increasing $\mathrm{Ca}^{2+}$ to $4 \mathrm{~mm}$ did not affect ripple dynamics (Fig. $8 D 3, E 3, n=2$ rats). No changes were recorded in PPI (Fig. 8F3) and on the amplitude of the PS (Fig. 8G3). These control data discarded the possibility that effects on ripples, PPI, and PS could be attributable to mechanical instabilities associated to delivery. Furthermore, an index of PPI (see Materials and Methods) positively correlated with the HFO frequency increase after delivery $(r=0.8014, p=$ 0.0302 , all data together), suggesting that individual variability at 0.5 and $20 \mathrm{~mm}$ EGTA reflected different degrees of circuitry impairment. Thus, $\mathrm{Ca}^{2+}$ decreases in vivo have similar effects on circuit dynamics as described in vitro. We also conclude that increasing $\mathrm{Ca}^{2+}$ concentration has a minor role in ripple organization, giving additional support to in vitro models of physiological-like SPW-HFO based in a relatively high $\mathrm{Ca}^{2+}$ content.

\section{Discussion}

We found that changing extracellular $\mathrm{Ca}^{2+}$ in a range of $1-3$ mu has a major influence in hippocampal circuits as tested in vitro. Using 2.5-3 $\mathrm{mM} \mathrm{Ca}^{2+}$ resulted in SPWs accompanied by HFO in the ripple range $(100-200 \mathrm{~Hz})$. Most pyramidal cells were inhibited by rhythmic IPSPs, similar to in vivo ripples (Ylinen et al., 1995; Wittner et al., 2007). In contrast, using $1-1.5 \mathrm{mM} \mathrm{Ca}^{2+}$ resulted in the emergence of larger and slightly faster HFOs $(>200 \mathrm{~Hz})$. Now, most pyramidal cells fired burst of action potentials, similar to fast ripples in epileptic rats (Ibarz et al., 2010). Enhanced excitability and imbalance of the E-I ratio underlie such dynamical reorganization, caused by a failure of GABA release that impairs disynaptic inhibition and promotes excessive firing synchronization. Locally manipulating $\mathrm{Ca}^{2+}$ in vivo had a similar effect on GABAergic transmission and ripple dynamics, suggesting that spontaneous fluctuations of basal $\mathrm{Ca}^{2+}$ might have profound effects on neuronal activity in situ. 
Table 3. Changes of synaptic efficacy and potency with extracellular $\mathrm{Ca}^{2+}$ concentration as tested in paired recordings

\begin{tabular}{lrr}
\hline & $3 \mathrm{~mm} \mathrm{Ca}^{2+}$ & $1 \mathrm{~mm} \mathrm{Ca}^{2+}$ \\
\hline Synaptic efficacy (including failures; $\mathrm{mV})$ & & \\
pyr-pyr $(n=3)$ & $1.66 \pm 0.85(0.54,1.95,2.51)$ & $1.07 \pm 0.22(0.16,1.21,1.86)$ \\
pyr-int $(n=2)$ & $6.68 \pm 5.71(2.64,10.73)$ & $5.29 \pm 5.73(1.24,9.35)$ \\
int-pyr $(n=2)$ & $-1.02 \pm 0.52(-1.39,-0.65)$ & $-0.19 \pm 0.09(-0.13,-0.26)$ \\
pyr-int-pyr $(n=2)$ & $-0.66 \pm 0.03(-0.64,-0.68)$ & $-0.34 \pm 0.05(-0.37,-0.31)$ \\
Synaptic potency (excluding failures; $\mathrm{mV})$ & & $1.36 \pm 0.92(0.39,1.46,2.23)$ \\
pyr-pyr $(n=3)$ & $1.69 \pm 1.01(0.59,1.95,2.55)$ & $6.14 \pm 5.54(2.22,10.06)$ \\
pyr-int $(n=2)$ & $7.39 \pm 5.47(3.55,11.27)$ & $-0.53 \pm 0.13(-0.44,-0.63)$ \\
int-pyr $(n=2)$ & $-1.06 \pm 0.46(-1.39,-0.74)$ & $-0.67 \pm 0.15(-0.56,-0.78)$ \\
pyr-int-pyr $(n=2)$ & $-0.78 \pm 0.11(-0.71,-0.86)$ & \\
\hline
\end{tabular}

Data are given as mean \pm SD. Individual values are given in parentheses.

Neuronal activity is strongly influenced by the level of extracellular ions, particularly $\mathrm{K}^{+}, \mathrm{Ca}^{2+}$, and $\mathrm{Mg}^{2+}$. Divalent cations have direct effects on intrinsic properties by altering the voltage dependence of $\mathrm{Na}^{+}$channels, i.e., a 10 -fold increase of $\mathrm{Ca}^{2+}$ shifts the sodium activation curve up to $25 \mathrm{mV}$ (Hille et al., 1975). Accordingly, we found hyperpolarization of $\sim 10 \mathrm{mV}$ of action potential threshold and enhanced excitability in pyramidal cells when $\mathrm{Ca}^{2+}$ is reduced. We also observed enhanced intrinsic bursting at 1 $\mathrm{mM} \mathrm{Ca}^{2+}$. Previous data show that activation curves of persistent $\mathrm{Na}^{+}$channels shift to more negative potentials at $1 \mathrm{~mm}$ $\mathrm{Ca}^{2+}$ (Su et al., 2001; Yue et al., 2005). These currents contribute to spike afterdepolarization that cause neurons to burst (Azouz et al., 1996; Menendez de la Prida et al., 2003), thus rendering cells hyperexcitable. Altogether, these data suggest profound effects of extracellular $\mathrm{Ca}^{2+}$ on intrinsic excitability. Because intrinsic bursting is a prerequisite for the emergence of pathological HFOs (Traub and Wong, 1982; Dzhala and Staley, 2004; Foffani et al., 2007), changes of cell ability to burst might account for faster HFOs when $\mathrm{Ca}^{2+}$ is decreased.

Changes of extracellular $\mathrm{Ca}^{2+}$ and $\mathrm{Mg}^{2+}$ also affect synaptic activity. $\mathrm{Ca}^{2+}$ has direct influence in transmitter release, and $\mathrm{Mg}^{2+}$ acts to voltage-dependent block NMDA. We found that reducing $\mathrm{Ca}^{2+}$ resulted in less frequent IPSCs and more EPSCs in both pyramidal cells and interneurons. Part of the increase of EPSC frequency is related to intrinsic excitability of pyramidal cells (Hille et al., 1975; Yue et al., 2005). Strangely, less frequent IPSCs contrasted with high interneuronal firing, pointing to defects of GABA release. With paired recordings, we confirmed that reducing $\mathrm{Ca}^{2+}$ to $1 \mathrm{~mm}$ impaired GABA release in interneurons, having weaker effects in glutamatergic transmission. Such a higher sensitivity of interneurons could be partly explained by
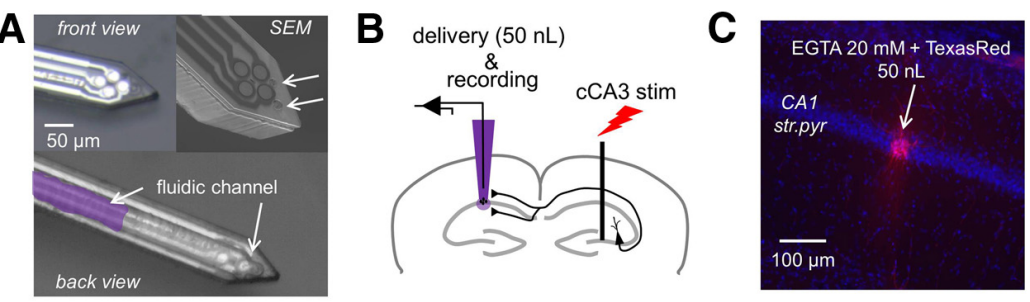

D1

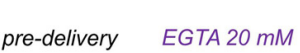

\section{D2 pre-delivery}

$1.5 \mathrm{mM} \mathrm{Ca}^{2+}$ EGTA $0.5 \mathrm{mM}$
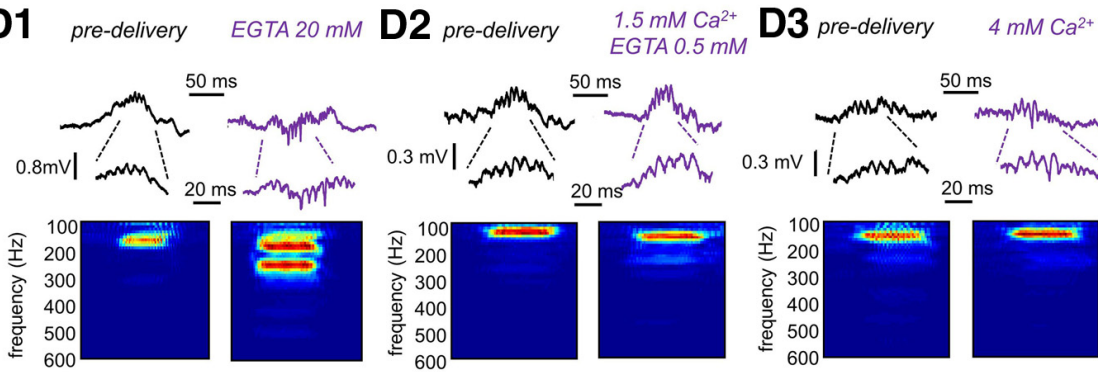

$50 \mathrm{~ms}$

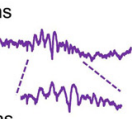
은
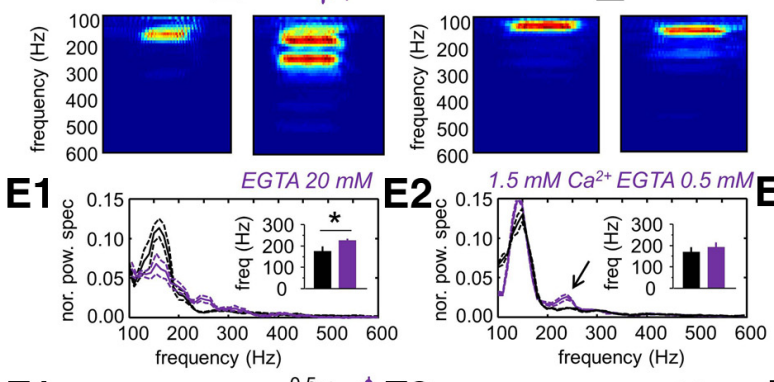

E3.
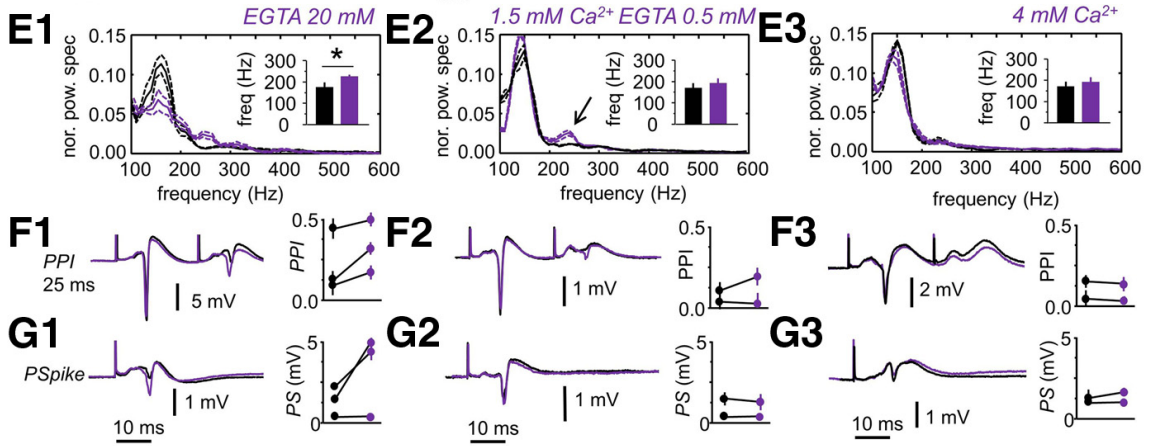

F3

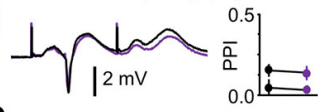

G3

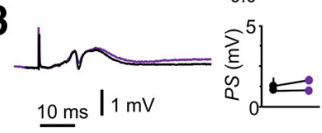

Figure 8. In vivo manipulation of extracellular $\mathrm{Ca}^{2+} . \boldsymbol{A}$, Front view and back view of the fprobe for simultaneous delivery and recording. The fluidic channel of $50 \times 20 \mu \mathrm{m}$ dimensions is visible in the back view. A picture from the scanning electron microscope (SEM) is shown at the top right to highlight outlet ports in the surface of the fprobe. Pictures from A. Altuna (IKERLAN, Arrasate, Spain). $\boldsymbol{B}$, Experimental design used in these experiments. Simultaneous delivery and recording were performed using the fprobe to target the CA1 stratum pyramidale while stimulating the contralateral CA3 region. $C$, Histological confirmation of delivery in one experiments aimed to inject $50 \mathrm{nl}$ of ACSF containing $20 \mathrm{~mm}$ EGTA in the dorsal hippocampus. The vital Texas Red dextran was used for localization purposes. str. pyr., Stratum pyramidale. D1, Effect of $20 \mathrm{~mm}$ EGTA on CA1 ripples. Note the mixed positive and negative spiky ripples induced by $20 \mathrm{~mm}$ EGTA. Enlarged traces show that all these are LFP events. D2, Effect of $0.5 \mathrm{~mm}$ EGTA and $1.5 \mathrm{~mm} \mathrm{C \textrm {a } ^ { 2 + }}$ on spontaneous ripples. D3, Delivery of ACSF with $4 \mathrm{~mm}$ did not cause clear changes in spontaneous ripples in CA1. E1, Normalized mean power spectrum of spontaneous SPW ripple events detected in CA1 before (black) and after (purple) delivery of ACSF with $20 \mathrm{~mm}$ EGTA (grand average, $n=4$ rats). Discontinuous lines represent $95 \%$ confidence. Inset shows the mean frequency peak of HFOs. Note reduction of ripple oscillatory power and increased contribution to the fast ripple range ( $>200 \mathrm{~Hz}$ ). E2, Same for $0.5 \mathrm{~mm}$ EGTA ( $n=2$ rats). Note the minor effect on ripple organization. E3, Delivery of ACSF with $4 \mathrm{~mm} \mathrm{Ca}^{2+}$ had poor effect on ripple frequency dynamics $(n=2$ rats). F1, Two stimuli separated by $25 \mathrm{~ms}$ were used to test for PPI of the maximal PS before and after delivery of $20 \mathrm{~mm}$ EGTA. Data on PPI ratio for $n=3$ rats. $F 2$, Effect of $0.5 \mathrm{~mm} \mathrm{Ca}^{2+}$ in PPI, $n=2$. F3, No effect were produced by $4 \mathrm{~mm} \mathrm{Ca}^{2+}$ on PPI, $n=$ 2. G1, Stimulation of intensities aimed to induce an intermediate PS were used to monitor CA1 pyramidal cell excitability before and after 20 mm EGTA. G2, Same for 0.5 mm EGTA. G3, Same for 4 mm Ca ${ }^{2+}$. 
Table 4. Typical ion concentrations used in different in vitro models of SPW HFOs

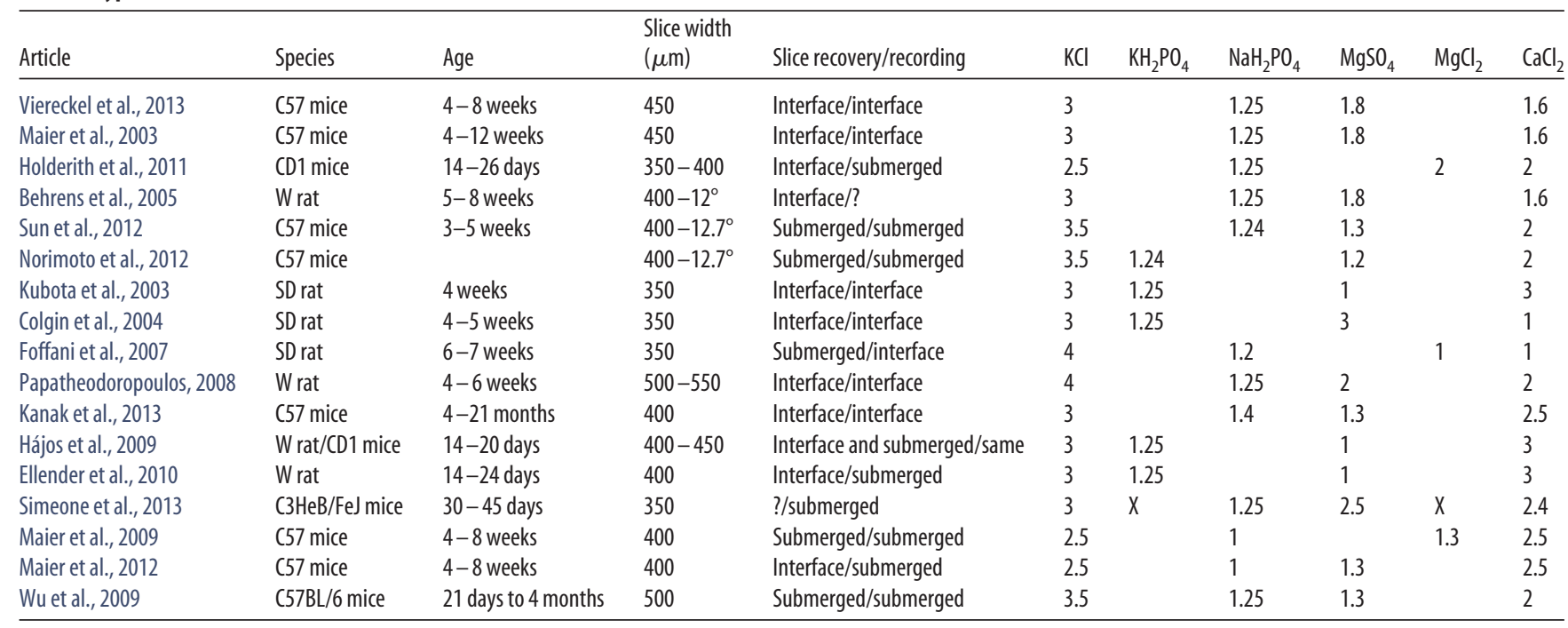

$\mathrm{NaCl}$ concentration ranged from 124 to $129 \mathrm{~mm}$. Glucose concentration was $10 \mathrm{~mm}$ in all cases. $\mathrm{NaHCO}_{3}$ concentration ranged from 21 to $26 \mathrm{~mm}$.

A physiological HFOs

B

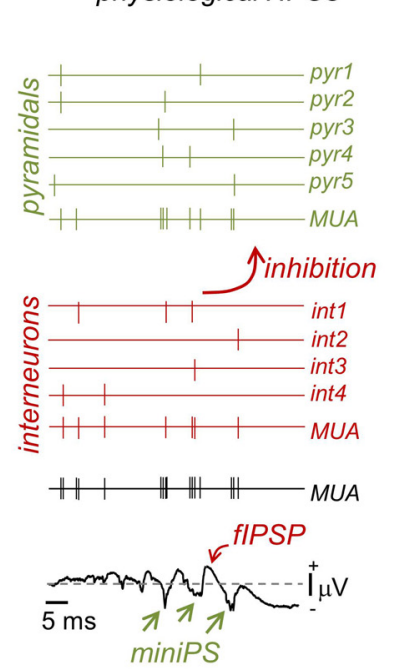

C
pathological HFOs

in-phase firing
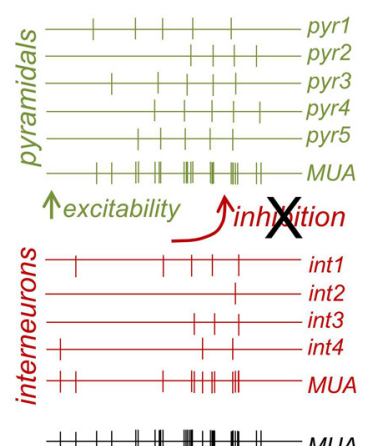

-

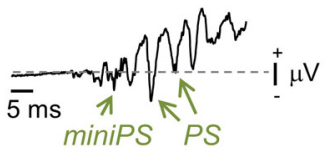

out-of-phase firing
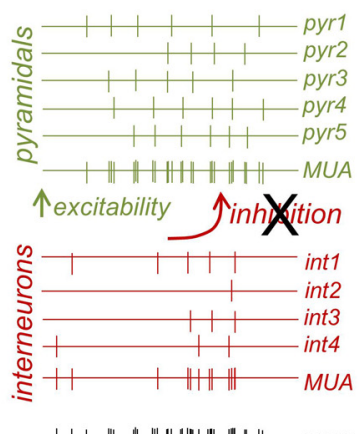

+ HW \|\|$\|W\|\|\| H \|-M U A$

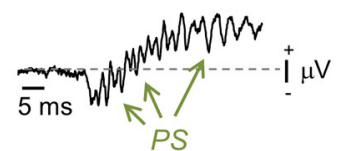

Figure 9. Schematic representation of circuit dynamics underlying physiological and pathological forms of hippocampal HFO. A, Physiological ripples. B, Pathological HFOs resulting from coordinated in-phase pyramidal firing. C, Pathological HFOs resulting from out-of-phase pyramidal firing. MUA, Multiunit activity; miniPS, mini-population spike.

the presence of calcium-binding buffers in GABAergic terminals, such as calbindin or parvalbumin. Although having different buffering kinetics, buffers might act to reduce intracellular $\mathrm{Ca}^{2+}$ beyond the limits required for reliably activating the release machinery (Köhr and Mody, 1991; Kamiya and Zucker, 1994; Caillard et al., 2000). Alternatively, cell-type differences in protein components of the SNARE complex could be linked with a different sensitivity to $\mathrm{Ca}^{2+}$ (Verdeiro et al., 2004). Other factors, such as failure of synchronous release or variability of action potential-induced $\mathrm{Ca}^{2+}$ influxes, might also account (Sasaki et al., 2012). Failure of GABAergic release in $1 \mathrm{mM} \mathrm{Ca}^{2+}$ directly affects the E-I balance through a disynaptic inhibitory collapse that results in runaway excitation and pathological activities (Miles et al., 1983; Miles and Wong, 1987; Menendez de la Prida and Gal, 2004; de la Prida et al., 2006). Disinhibition of dendritic compartments could also release pyramidal cell bursting (Royer et al., 2012).
How relevant are these in vitro changes of $\mathrm{Ca}^{2+}$ to the living brain? The resting level of $\mathrm{Ca}^{2+}$ is in a range from 1.2 to 1.5 $\mathrm{mm}$, but state-dependent reduction has been reported. During slow oscillations, $\mathrm{Ca}^{2+}$ drops to $\sim 20 \%$ in association with the depolarizing phase of the wave (Massimini and Amzica, 2001). Moreover, changes of $\mathrm{Ca}^{2+}$ have been seen to precede seizures (Heinemann et al., 1977). We confirmed that manipulating extracellular $\mathrm{Ca}^{2+}$ in the hippocampus in situ had a similar effect on disynaptic inhibition, pyramidal cell excitability, and ripple dynamics as those described in vitro. Therefore, fluctuating $\mathrm{Ca}^{2+}$ in vivo could be potentially linked with dynamical E-I changes in normal and epileptic conditions (Dzhala and Staley, 2003; Derchansky et al., 2008; Gnatkovsky et al., 2008; Huberfeld et al., 2011; Sabolek et al., 2012).

However, an extracellular $\mathrm{Ca}^{2+}$ concentration of $3 \mathrm{~mm}$ appears too high when compared with the typical range measured in situ. This usage was introduced to model SPW in vitro of similar dynamics than in vivo events (Kubota et al., 2003; Ellender et al., 2010), but similar physiological-like ripples have been described using standard $\mathrm{Ca}^{2+}$ concentrations (Maier et al., 2009, 2011; Table 4). The transverse hippocampal slice preparation is a popular method to gain additional insights into the neuronal mechanisms of oscillations (Skrede and Westgaard, 1971). However, major differences between slices and the intact brain, including network connectivity, metabolic demands, and neuromodulatory influence, strongly affect the slice ability to generate in vivo-like oscillations. It seems that the precise inhibitory control accompanying ripples in vivo is easily disrupted in vitro, probably by slicing and storage conditions (Tanaka et al., 2008; Maier et al., 2009, Hájos et al., 2009). Even using mice or rats to prepare hippocampal slices would make major differences in the proportion of the intrahippocampal circuit that is pre- 
served. When hippocampal slices of normal animals are submitted to mild increases of excitability-high $\mathrm{K}^{+}(4-6 \mathrm{~mm})$, low $\mathrm{Ca}^{2+}(0.5-1 \mathrm{~mm})$, and low $\mathrm{Mg}^{2+}(0-0.5 \mathrm{~mm})$ - synchronous bursts and HFOs are easily released (Dzhala and Staley, 2004; Karlócai et al., 2014). Other manipulations, such as highfrequency stimulation that induces long-term potentiation and cholinergic and adrenergic modulation and disinhibition, are shown to affect the degree of firing coordination during HFOs (Miles and Wong, 1987; Behrens et al., 2005; Liotta et al., 2011; Ul Haq et al., 2012). Therefore, physiological ripple-like HFOs appear too fragile and dependent on a precise E-I coordination, a breakdown of which easily transforms them into pathological HFOs (Dzhala and Staley, 2004; Foffani et al., 2007).

Classification of ripples and fast ripples in vitro is based on tradition and semantic criteria, but a rigorous definition is lacking. A major question is what is normal and what is not in hippocampal HFOs, given that neither their frequency nor their LFP and CSD signatures are unequivocal (Engel et al., 2009: Jefferys et al., 2012). We suggest that the dynamic of neuronal synchronization during SPWs is highly informative on the excitability state of the circuit (Takano et al., 2012). A precisely balanced state of excitation and inhibition is reflected in their instantaneous coactivation (Borg-Graham, 2001; Shu et al., 2003, Okun and Lampl, 2008; Atallah and Scanziani, 2009). Accordingly, pyramidal cell firing holds no more than 10 times gain increases in $\sim 20 \%$ of cells during physiological ripples (Csicsvari et al., 2000). Under this condition, HFOs rarely accelerate because most neurons were under strong disynaptic inhibitory control that prevents excessive neuronal firing (Fig. 9A). Rhythmic IPSP activity is reflected as positive deflections of the LFP, and phasic pyramidal firing is coordinated by E-I coordination (Ellender et al., 2010; Reichinnek et al., 2010; Maier et al., 2011). Coherent phasic firing of small groups of pyramidal cells gives rise to small PSs (Fig. 9A, miniPS; Suzuki and Smith, 1988; Buzsáki et al., 1992; Schomburg et al., 2012).

Quite in contrast, pathological HFOs do reflect unbalanced synaptic states dominated by excitation. A disproportionately large number of pyramidal cells are now engaged in collective neuronal discharges after failure of disynaptic inhibition (Fig. $9 B$ ). Pathological HFOs would necessarily reflect a disinhibitory state in the form of slightly accelerated cycles that now represent large spiky and repetitive potentials riding on a depolarizing envelop (Fig. 9B). Typically, faster HFOs invade the fast ripple band, and emergent components reflect in-phase and out-ofphase HFO cycles (Fig. 9C; Ibarz et al., 2010). Recent work has shown similar effects of enhanced excitability and E-I collapse in the emergence of pathological events (Karlócai et al., 2014). Stronger fields probably favor other types of electric interactions and promote synchronization (Jefferys, 1995). Impairment of GABAergic inhibition occurs in the epileptic hippocampus after loss of interneurons (Sloviter, 1987; Cossart et al., 2001), modification of existing inhibitory pathways (Morin et al., 1998; Shao and Dudek, 2005), and deficits of $\mathrm{GABA}_{\mathrm{A}}$ release (Hirsch et al., 1999). Our results show that all of these changes would affect recruitment properties in the circuit attributable to ineffectiveness of disynaptic inhibition to constrain recurrent excitatory activity. Whether in situ changes of $\mathrm{Ca}^{2+}$ and other relevant ions occur in the normal and epileptic brain is open to additional investigation. On this basis, the E-I balance could even change dynamically, like during transition to seizures or because of statedependent fluctuations to affect the expression of hippocampal HFOs in an apparently nonpredictable way. Our data suggest that looking at the dynamic behavior of HFOs would provide mechanistic information on the circuit state.

\section{Notes}

Supplemental material for this article is available at http://hippocircuitlab.com/2013/10/interface-chamber-for-visual-patch-recordingin-slices/. Supplemental Figure 1 is available at http://dx.doi.org/ $10.6084 / \mathrm{m} 9$. figshare.704836 and Supplemental Figure 2 is available at http://dx.doi.org/10.6084/m9.figshare.704837. This material has not been peer reviewed.

\section{References}

Altuna A, Bellistri E, Cid E, Aivar P, Gal B, Berganzo J, Gabriel G, Guimerà A, Villa R, Fernández LJ, Menendez de la Prida L (2013) SU-8 based microprobes for simultaneous neural depth recording and drug delivery in the brain. Lab Chip 13:1422-1430. CrossRef Medline

Atallah BV, Scanziani M (2009) Instantaneous modulation of gamma oscillation frequency by balancing excitation with inhibition. Neuron 62:566577. CrossRef Medline

Ayala GF, Dichter M, Gumnit RJ, Matsumoto H, Spencer WA (1973) Genesis of epileptic interictal spikes. New knowledge of cortical feedback systems suggests a neurophysiological explanation of brief paroxysms. Brain Res 52:1-17. CrossRef Medline

Azouz R, Jensen MS, Yaari Y (1996) Ionic basis of spike after-depolarization and burst generation in adult rat hippocampal CA1 pyramidal cells. J Physiol 492:211-223. Medline

Bazelot M, Dinocourt C, Cohen I, Miles R (2010) Unitary inhibitory field potentials in the CA3 region of rat hippocampus. J Physiol 588:20772090. CrossRef Medline

Behrens CJ, van den Boom LP, de Hoz L, Friedman A, Heinemann U (2005) Induction of sharp wave-ripple complexes in vitro and reorganization of hippocampal networks. Nat Neurosci 8:1560-1567. CrossRef Medline

Bellistri E, Aguilar J, Brotons-Mas JR, Foffani G, de la Prida LM (2013) Basic properties of somatosensory-evoked responses in the dorsal hippocampus of the rat. J Physiol 591:2667-2686. CrossRef Medline

Beyeler A, Retailleau A, Molter C, Mehidi A, Szabadics J, Leinekugel X (2013) Recruitment of perisomatic inhibition during spontaneous hippocampal activity in vitro. PLoS One 8:e66509. CrossRef Medline

Borg-Graham LJ (2001) The computation of directional selectivity in the retina occurs prior to the ganglion cell. Nat Neurosci 4:176-183. CrossRef Medline

Bragin A, Engel J Jr, Wilson CL, Fried I, Mathern GW (1999) Hippocampal and entorhinal cortex high-frequency oscillations $(100-500 \mathrm{~Hz})$ in human epileptic brain and in kainic acid-treated rats with chronic seizures. Epilepsia 40:127-137. CrossRef Medline

Bragin A, Benassi SK, Kheiri F, Engel J Jr (2011) Further evidence that pathologic high-frequency oscillations are bursts of population spikes derived from recordings of identified cells in dentate gyrus. Epilepsia 52:45-52. CrossRef Medline

Buzsáki G, Leung LW, Vanderwolf CH (1983) Cellular bases of hippocampal EEG in the behaving rat. Brain Res 287:139-171. Medline

Buzsáki G, Horváth Z, Urioste R, Hetke J, Wise K (1992) High-frequency network oscillation in the hippocampus. Science 256:1025-1027. CrossRef Medline

Caillard O, Moreno H, Schwaller B, Llano I, Celio MR, Marty A (2000) Role of the calcium-binding protein parvalbumin in short-term synaptic plasticity. Proc Natl Acad Sci U S A 97:13372-13377. CrossRef Medline

Colgin LL, Kubota D, Jia Y, Rex CS, Lynch G (2004) Long-term potentiation is impaired in rat hippocampal slices that produce spontaneous sharp waves. J Physiol 558:953-961. CrossRef Medline

Cossart R, Dinocourt C, Hirsch JC, Merchan-Perez A, De Felipe J, Ben-Ari Y, Esclapez M, Bernard C (2001) Dendritic but not somatic GABAergic inhibition is decreased in experimental epilepsy. Nat Neurosci 4:52-62. CrossRef Medline

Csicsvari J, Hirase H, Czurkó A, Mamiya A, Buzsáki G (1999) Oscillatory coupling of hippocampal pyramidal cells and interneurons in the behaving rat. J Neurosci 19:274-287. Medline

Csicsvari J, Hirase H, Mamiya A, Buzsáki G (2000) Ensemble patterns of hippocampal CA3-CA1 neurons during sharp wave-associated population events. Neuron 28:585-594. CrossRef Medline

de la Prida LM, Huberfeld G, Cohen I, Miles R (2006) Threshold behavior in 
the initiation of hippocampal population bursts. Neuron 49:131-142. CrossRef Medline

Derchansky M, Jahromi SS, Mamani M, Shin DS, Sik A, Carlen PL (2008) Transition to seizures in the isolated immature mouse hippocampus: a switch from dominant phasic inhibition to dominant phasic excitation. J Physiol 586:477-494. Medline

Draguhn A, Traub RD, Schmitz D, Jefferys JGR (1998) Electrical coupling underlies high-frequency oscillations in the hippocampus in vitro. Nature 394:189-192. CrossRef Medline

Dupret D, O’Neill J, Pleydell-Bouverie B, Csicsvari J (2010) The reorganization and reactivation of hippocampal maps predict spatial memory performance. Nat Neurosci 13:995-1002. CrossRef Medline

Dzhala VI, Staley KJ (2003) Transition from interictal to ictal activity in limbic networks in vitro. J Neurosci 23:7873-7880. Medline

Dzhala VI, Staley KJ (2004) Mechanisms of fast ripples in the hippocampus. J Neurosci 24:8896-8906. CrossRef Medline

Ellender TJ, Nissen W, Colgin LL, Mann EO, Paulsen O (2010) Priming of hippocampal population bursts by individual perisomatic-targeting interneurons. J Neurosci 30:5979-5991. CrossRef Medline

Engel J Jr, Bragin A, Staba R, Mody I (2009) High-frequency oscillations: what is normal and what is not? Epilepsia 50:598-604. CrossRef Medline

Foffani G, Uzcategui YG, Gal B, Menendez de la Prida L (2007) Reduced spike-timing reliability correlates with the emercience of fast ripples in the rat epileptic hippocampus. Neuron 55:930-941. CrossRef Medline

Gibson IM, McIlwain H (1965) Continuous recordings of changes in membrane potential in mammalian cerebral tissues in vitro; recovery after depolarization by added substances. J Physiol 176:261-283. Medline

Glickfeld LL, Roberts JD, Somogyi P, Scanziani M (2009) Interneurons hyperpolarize pyramidal cells along their entire somatodendritic axis. Nat Neurosci 12:21-23. CrossRef Medline

Gnatkovsky V, Librizzi L, Trombin F, de Curtis M (2008) Fast activity at seizure onset is mediated by inhibitory circuits in the entorhinal cortex in vitro. Ann Neurol 64:674-686. CrossRef Medline

Hájos N, Ellender TJ, Zemankovics R, Mann EO, Exley R, Cragg SJ, Freund TF, Paulsen O (2009) Maintaining network activity in submerged hippocampal slices: importance of oxygen supply. Eur J Neurosci 29:319327. CrossRef Medline

Hájos N, Karlócai MR, Németh B, Ulbert I, Monyer H, Szabó G, Erdélyi F, Freund TF, Gulyás AI (2013) Input-output features of anatomically identified CA3 neurons during hippocampal sharp wave/ripple oscillation in vitro. J Neurosci 33:11677-11691. CrossRef Medline

Heinemann U, Lux HD, Gutnick MJ (1977) Extracellular free calcium and potassium during paroxsmal activity in the cerebral cortex of the cat. Exp Brain Res 27:237-243. Medline

Hille B, Woodhull AM, Shapiro BI (1975) Negative surface charge near sodium channels of nerve: divalent ions, monovalent ions, and $\mathrm{pH}$. Philos Trans R Soc Lond B Biol Sci 270:301-318. CrossRef Medline

Hirsch JC, Agassandian C, Merchán-Pérez A, Ben-Ari Y, DeFelipe J, Esclapez M, Bernard C (1999) Deficit of quantal release of GABA in experimental models of temporal lobe epilepsy. Nat Neurosci 2:499-500. CrossRef Medline

Holderith N, Németh B, Papp OI, Veres JM, Nagy GA, Hájos N (2011) Cannabinoids attenuate hippocampal $\gamma$ oscillations by suppressing excitatory synaptic input onto CA3 pyramidal neurons and fast spiking basket cells. J Physiol 589:4921-4934. CrossRef Medline

Huberfeld G, Menendez de la Prida L, Pallud J, Cohen I, Le Van Quyen M, Adam C, Clemenceau S, Baulac M, Miles R (2011) Glutamatergic preictal discharges emerge at the transition to seizure in human epilepsy. Nat Neurosci 14:627-634. CrossRef Medline

Ibarz JM, Foffani G, Cid E, Inostroza M, Menendez de la Prida L (2010) Emergent dynamics of fast ripples in the epileptic hippocampus. J Neurosci 30:16249-16261. CrossRef Medline

Jefferys JG, Menendez de la Prida L, Wendling F, Bragin A, Avoli M, Timofeev I, Lopes da Silva FH (2012) Mechanisms of physiological and epileptic HFO generation. Prog Neurobiol 98:250-264. CrossRef Medline

Jefferys JGR (1995) Nonsynaptic modulation of neuronal activity in the brain: electric currents and extracellular ions. Physiol Rev 75:689-723. Medline

Jones RS, Heinemann U (1987) Abolition of the orthodromically evoked IPSP of CA1 pyramidal cells before the EPSP during washout of calcium from hippocampal slices. Exp Brain Res 65:676-680. Medline
Kamiya H, Zucker RS (1994) Residual $\mathrm{Ca}^{2+}$ and short-term synaptic plasticity. Nature 371:603-606. CrossRef Medline

Kanak DJ, Rose GM, Zaveri HP, Patrylo PR (2013) Altered network timing in the CA3-CA1 circuit of hippocampal slices from aged mice. PLoS One. 8:e61364. CrossRef Medline

Karlócai MR, Kohus Z, Káli S, Ulbert I, Szabó G, Máté Z, Freund TF, Gulyás AI (2014) Physiological sharp wave-ripples and interictal events in vitro: what's the difference? Brain. Advance online publication. Retrieved January 20, 2014. doi:10.1093/brain/awt348. CrossRef Medline

Köhr G, Mody I (1991) Endogenous intracellular calcium buffering and the activation/inactivation of HVA calcium currents in rat dentate gyrus granule cells. J Gen Physiol 98:941-967. CrossRef Medline

Kubota D, Colgin LL, Casale M, Brucher FA, Lynch G (2003) Endogenous waves in hippocampal slices. J Neurophysiol 89:81-89. Medline

Lee AK, Wilson MA (2002) Memory of sequential experience in the hippocampus during slow wave sleep. Neuron 36:1183-1194. CrossRef Medline

Liotta A, Caliskan G, ul Haq R, Hollnagel JO, Rösler A, Heinemann U, Behrens CJ (2011) Partial disinhibition is required for transition of stimulus-induced sharp wave-ripple complexes into recurrent epileptiform discharges in rat hippocampal slices. J Neurophysiol 105:172-187. CrossRef Medline

Maier N, Nimmrich V, Draguhn A (2003) Cellular and network mechanisms underlying spontaneous sharp wave-ripple complexes in mouse hippocampal slices. J Physiol 550:873-887. CrossRef Medline

Maier N, Morris G, Johenning FW, Schmitz D (2009) An approach for reliably investigating hippocampal sharp wave-ripples in vitro. PLoS One 4:e6925. CrossRef Medline

Maier N, Tejero-Cantero A, Dorrn AL, Winterer J, Beed PS, Morris G, Kempter R, Poulet JF, Leibold C, Schmitz D (2011) Coherent phasic excitation during hippocampal ripples. Neuron 72:137-152. CrossRef Medline

Maier N, Morris G, Schuchmann S, Korotkova T, Ponomarenko A, Böhm C, Wozny C, Schmitz D (2012) Cannabinoids disrupt hippocampal sharp wave-ripples via inhibition of glutamate release. Hippocampus 22:13501362. CrossRef Medline

Marchionni I, Maccaferri G (2009) Quantitative dynamics and spatial profile of perisomatic GABAergic input during epileptiform synchronization in the CA1 hippocampus. J Physiol 587:5691-5708. CrossRef Medline

Massimini M, Amzica F (2001) Extracellular calcium fluctuations and intracellular potentials in the cortex during the slow sleep oscillation. J Neurophysiol 85:1346-1350. Medline

Menendez de la Prida L, Gal B (2004) Synaptic contributions to focal and widespread spatiotemporal dynamics in the isolated rat subiculum in vitro. J Neurosci 24:5525-5536. CrossRef Medline

Menendez de la Prida L, Suarez F, Pozo MA (2003) Electrophysiological and morphological diversity of neurons from the rat subicular complex in vitro. Hippocampus 13:728-744. CrossRef Medline

Miles R, Wong RK (1987) Inhibitory control of local excitatory circuits in the guinea-pig hippocampus. J Physiol 388:611-629. Medline

Morin F, Beaulieu C, Lacaille JC (1998) Cell-specific alterations in synaptic properties of hippocampal CA1 interneurons after kainate treatment. J Neurophysiol 80:2836-2847. Medline

Norimoto H, Mizunuma M, Ishikawa D, Matsuki N, Ikegaya Y (2012) Muscarinic receptor activation disrupts hippocampal sharp wave-ripples. Brain Res. 1461:1-9. CrossRef Medline

Okun M, Lampl I (2008) Instantaneous correlation of excitation and inhibition during ongoing and sensory-evoked activities. Nat Neurosci 11: 535-537. CrossRef Medline

Papatheodoropoulos C (2008) A possible role of ectopic action potentials in the in vitro hippocampal sharp wave-ripple complexes. Neuroscience 157:495-501. CrossRef Medline

Papatheodoropoulos C, Kostopoulos G (2002) Spontaneous, low frequency (approximately $2-3 \mathrm{~Hz}$ ) field activity generated in rat ventral hippocampal slices perfused with normal medium. Brain Res Bull 57:187-193. CrossRef Medline

Papp OI, Karlócai MR, Tóth IE, Freund TF, Hájos N (2013) Different input and output properties characterize parvalbumin-positive basket and axoaxonic cells in the hippocampal CA3 subfield. Hippocampus. Advance online publication. Retrieved January 20, 2014. doi:10.1002/hipo.22147. CrossRef Medline

Reichinnek S, Künsting T, Draguhn A, Both M (2010) Field potential signa- 
ture of distinct multicellular activity patterns in the mouse hippocampus. J Neurosci 30:15441-15449. CrossRef Medline

Royer S, Zemelman BV, Losonczy A, Kim J, Chance F, Magee JC, Buzsáki G (2012) Control of timing, rate and bursts of hippocampal place cells by dendritic and somatic inhibition. Nat Neurosci 15:769-775. CrossRef Medline

Sabolek HR, Swiercz WB, Lillis KP, Cash SS, Huberfeld G, Zhao G, Ste Marie L, Clemenceau S, Barsh G, Miles R, Staley KJ (2012) A candidate mechanism underlying the variance of interictal spike propagation. J Neurosci 32:3009-3021. CrossRef Medline

Sasaki T, Matsuki N, Ikegaya Y (2012) Heterogeneity and independency of unitary synaptic outputs from hippocampal CA3 pyramidal cells. J Physiol 590:4869-4880. CrossRef Medline

Schneiderman JH (1986) Low concentrations of penicillin reveal rhythmic, synchronous synaptic potentials in hippocampal slice. Brain Res 398:231241. CrossRef Medline

Schomburg EW, Anastassiou CA, Buzsáki G, Koch C (2012) The spiking component of oscillatory extracellular potentials in the rat hippocampus. J Neurosci 32:11798-11811. CrossRef Medline

Schwartzkroin PA, Prince DA (1978) Cellular and field potential properties of epileptogenic hippocampal slices. Brain Res 147:117-130. CrossRef Medline

Shao LR, Dudek FE (2005) Changes in mIPSCs and sIPSCs after kainate treatment: evidence for loss of inhibitory input to dentate granule cells and possible compensatory responses. J Neurophysiol 94:952-960. CrossRef Medline

Shu Y, Hasenstaub A, McCormick DA (2003) Turning on and off recurrent balanced cortical activity. Nature 423:288-293. CrossRef Medline

Simeone TA, Simeone KA, Samson KK, Kim do Y, Rho JM (2013) Loss of the Kv1.1 potassium channel promotes pathologic sharp waves and high frequency oscillations in in vitro hippocampal slices. Neurobiol Dis 54:6881. CrossRef Medline

Skaggs WE, McNaughton BL (1996) Replay of neuronal firing sequences in rat hippocampus during sleep following spatial experience. Science 271: 1870-1873. CrossRef Medline

Skaggs WE, McNaughton BL, Permenter M, Archibeque M, Vogt J, Amaral DG, Barnes CA (2007) EEG sharp waves and sparse ensemble unit activity in the macaque hippocampus. J Neurophysiol 98:898-910. CrossRef Medline

Skrede KK, Westgaard RH (1971) The transverse hippocampal slice: a welldefined cortical structure maintained in vitro. Brain Res 35:589-593. CrossRef Medline

Sloviter RS (1987) Decreased hippocampal inhibition and a selective loss of interneurons in experimental epilepsy. Science 235:73-76. CrossRef Medline

Spampanato J, Mody I (2007) Spike timing of lacunosom-moleculare targeting interneurons and CA3 pyramidal cells during high-frequency network oscillations in vitro. J Neurophysiol 98:96-104. CrossRef Medline

Su H, Alroy G, Kirson ED, Yaari Y (2001) Extracellular calcium modulates persistent sodium current-dependent burst-firing in hippocampal pyramidal neurons. J Neurosci 21:4173-4182. Medline

Suárez LM, Cid E, Gal B, Inostroza M, Brotons-Mas JR, Gómez-Domínguez D, de la Prida LM, Solís JM (2012) Systemic injection of kainic acid differently affects LTP magnitude depending on its epileptogenic efficiency. PLoS One 7:e48128. CrossRef Medline

Sullivan D, Csicsvari J, Mizuseki K, Montgomery S, Diba K, Buzsáki G (2011)
Relationships between hippocampal sharp waves, ripples, and fast gamma oscillation: influence of dentate and entorhinal cortical activity. J Neurosci 31:8605-8616. CrossRef Medline

Sun Y, Norimoto H, Pu XP, Matsuki N, Ikegaya Y (2012) Cannabinoid receptor activation disrupts the internal structure of hippocampal sharp wave-ripple complexes. J Pharmacol Sci 118:288-294. CrossRef Medline

Suzuki SS, Smith GK (1988) Spontaneous EEG spikes in the normal hippocampus. II. Relations to synchronous burst discharges. Electroencephalogr Clin Neurophysiol 69:532-540. Medline

Takano H, McCartney M, Ortinski PI, Yue C, Putt ME, Coulter DA (2012) Deterministic and stochastic neuronal contributions to distinct synchronous CA3 network bursts. J Neurosci 32:4743-4754. CrossRef Medline

Tanaka Y, Tanaka Y, Furuta T, Yanagawa Y, Kaneko T (2008) The effects of cutting solutions on the viability of GABAergic interneurons in cerebral cortical slices of adult mice. J Neurosci Methods 171:118-125. CrossRef Medline

Traub RD, Wong RK (1982) Cellular mechanism of neuronal synchronization in epilepsy. Science 216:745-747. CrossRef Medline

Uematsu M, Hirai Y, Karube F, Ebihara S, Kato M, Abe K, Obata K, Yoshida S, Hirabayashi M, Yanagawa Y, Kawaguchi Y (2008) Quantitative chemical composition of cortical GABAergic neurons revealed in transgenic venus-expressing rats. Cereb Cortex 18:315-330. CrossRef Medline

Ul Haq R, Liotta A, Kovacs R, Rösler A, Jarosch MJ, Heinemann U, Behrens CJ (2012) Adrenergic modulation of sharp wave-ripple activity in rat hippocampal slices. Hippocampus 22:516-533. CrossRef Medline

Verderio C, Pozzi D, Pravettoni E, Inverardi F, Schenk U, Coco S, ProuxGillardeaux V, Galli T, Rossetto O, Frassoni C, Matteoli M (2004) SNAP-25 modulation of calcium dynamics underlies differences in GABAergic and glutamatergic responsiveness to depolarization. Neuron 41:599-610. CrossRef Medline

Viereckel T, Kostic M, Bähner F, Draguhn A, Both M (2013) Effects of the GABA-uptake blocker NNC-711 on spontaneous sharp wave-ripple complexes in mouse hippocampal slices. Hippocampus 23:323-329. CrossRef Medline

Wittner L, Henze DA, Záborszky L, Buzsáki G (2007) Three-dimensional reconstruction of the axon arbor of a CA3 pyramidal cell recorded and filled in vivo. Brain Struct Funct 212:75-83. CrossRef Medline

Wu C, Asl MN, Gillis J, Skinner FK, Zhang L (2005) An in vitro model of hippocampal sharp waves: regional initiation and intracellular correlates. J Neurophysiol 94:741-753. CrossRef Medline

Wu C, Wong T, Wu X, Sheppy E, Zhang L (2009) Adenosine as an endogenous regulating factor of hippocampal sharp waves. Hippocampus 19: 205-220. CrossRef Medline

Ylinen A, Bragin A, Nádasdy Z, Jandó G, Szabó I, Sik A, Buzsáki G (1995) Sharp wave-associated high-frequency oscillation $(200 \mathrm{~Hz})$ in the intact hippocampus: network and intracellular mechanisms. J Neurosci 15:3046. Medline

Yue C, Remy S, Su H, Beck H, Yaari Y (2005) Proximal persistent $\mathrm{Na}^{+}$ channels drive spike afterdepolarizations and associated bursting in adult CA1 pyramidal cells. J Neurosci 25:9704-9720. CrossRef Medline

Zanotti S, Charles A (1997) Extracellular calcium sensing by glial cells: low extracellular calcium induces intracellular calcium release and intercellular signaling. J Neurochem 69:594-602. Medline

Zijlmans M, Jiruska P, Zelmann R, Leijten FS, Jefferys JG, Gotman J (2012) High-frequency oscillations as a new biomarker in epilepsy. Ann Neurol 71:169-178. CrossRef Medline 